\title{
An improved and homogeneous altimeter sea level record from the ESA Climate Change Initiative
}

\author{
Jean-François Legeais ${ }^{1}$, Michaël Ablain ${ }^{1}$, Lionel Zawadzki ${ }^{1}$, Hao Zuo ${ }^{2}$, Johnny A. Johannessen ${ }^{3}$, \\ Martin G. Scharffenberg ${ }^{4}$, Luciana Fenoglio-Marc ${ }^{5}$, M. Joana Fernandes ${ }^{6,7}$, Ole Baltazar Andersen ${ }^{8}$, \\ Sergei Rudenko $^{9,10}$, Paolo Cipollini ${ }^{11}$, Graham D. Quartly ${ }^{12}$, Marcello Passaro ${ }^{9}$, Anny Cazenave ${ }^{13,14}$, \\ and Jérôme Benveniste ${ }^{15}$ \\ ${ }^{1}$ Collecte Localisation Satellite (CLS), 31520 Ramonville-Saint-Agne, France \\ ${ }^{2}$ European Centre for Medium-Range Weather Forecasts, Reading, UK \\ ${ }^{3}$ Nansen Environmental and Remote Sensing Center (NERSC), Bergen, Norway \\ ${ }^{4}$ University of Hamburg, Hamburg, Germany \\ ${ }^{5}$ University of Bonn, Bonn, Germany \\ ${ }^{6}$ Faculdade de Ciências, Universidade do Porto, 4169-007 Porto, Portugal \\ ${ }^{7}$ Centro Interdisciplinar de Investigação Marinha e Ambiental (CIIMAR), 4450-208 Matosinhos, Portugal \\ ${ }^{8}$ DTU Space, 2800 Kongens Lyngby, Denmark \\ ${ }^{9}$ Deutsches Geodätisches Forschungsinstitut, Technische Universität München, 80333 Munich, Germany \\ ${ }^{10}$ Helmholtz Centre Potsdam - GFZ German Research Centre for Geosciences, 14473 Potsdam, Germany \\ ${ }^{11}$ National Oceanography Centre, Southampton, SO14 3ZH, UK \\ ${ }^{12}$ Plymouth Marine Laboratory, Plymouth, PL13DH, UK \\ ${ }^{13}$ LEGOS, 31400 Toulouse, France \\ ${ }^{14}$ ISSI, Bern, Switzerland \\ ${ }^{15}$ ESA/ESRIN, 00044 Frascati, Italy
}

Correspondence: Jean-François Legeais (jlegeais@cls.fr)

Received: 13 October 2017 - Discussion started: 17 October 2017

Revised: 21 December 2017 - Accepted: 28 December 2017 - Published: 12 February 2018

\begin{abstract}
Sea level is a very sensitive index of climate change since it integrates the impacts of ocean warming and ice mass loss from glaciers and the ice sheets. Sea level has been listed as an essential climate variable (ECV) by the Global Climate Observing System (GCOS). During the past 25 years, the sea level ECV has been measured from space by different altimetry missions that have provided global and regional observations of sea level variations. As part of the Climate Change Initiative (CCI) program of the European Space Agency (ESA) (established in 2010), the Sea Level project (SL_cci) aimed to provide an accurate and homogeneous long-term satellite-based sea level record. At the end of the first phase of the project (2010-2013), an initial version (v1.1) of the sea level ECV was made available to users (Ablain et al., 2015). During the second phase of the project (2014-2017), improved altimeter standards were selected to produce new sea level products (called SL_cci v2.0) based on nine altimeter missions for the period 19932015 (https://doi.org/10.5270/esa-sea_level_cci-1993_2015-v_2.0-201612; Legeais and the ESA SL_cci team, 2016c). Corresponding orbit solutions, geophysical corrections and altimeter standards used in this v2.0 dataset are described in detail in Quartly et al. (2017). The present paper focuses on the description of the SL_cci v2.0 ECV and associated uncertainty and discusses how it has been validated. Various approaches have been used for the quality assessment such as internal validation, comparisons with sea level records from other groups and with in situ measurements, sea level budget closure analyses and comparisons with model outputs. Compared with the previous version of the sea level ECV, we show that use of improved geophysical corrections, careful bias reduction between missions and inclusion of new altimeter missions lead to improved sea level products with reduced uncertainties on different spatial and temporal scales. However, there is still room for improvement
\end{abstract}


since the uncertainties remain larger than the GCOS requirements (GCOS, 2011). Perspectives on subsequent evolution are also discussed.

\section{Introduction}

Present-day global mean sea level (GMSL) rise primarily reflects the amount of heat added to the ocean, as well as land ice melt in response to anthropogenic global warming (e.g. IPCC, 2013; von Schuckmann et al., 2016). Accurate monitoring of sea level is required to better understand its variability and distinguish between natural and anthropogenic forcing factors as the origin of observed changes. It also allows validation of climate models developed for projecting future changes, as the models reproduce present-day and recent-past changes. Since 1993, satellite altimetry missions have delivered accurate sea level measurements, allowing the monitoring of sea level variations on different spatial and temporal scales (e.g. Pujol et al., 2016; Ablain et al., 2017; Escudier et al., 2017). About a decade ago, the Global Climate Observing System (GCOS) defined a list of key parameters of the Earth system, or "essential climate variables" (ECVs) that need to be accurately monitored in order to meet the needs of the climate change community (Bojinski et al., 2014). To respond to this need for climate-quality satellite data, the European Space Agency (ESA) developed the "Climate Change Initiative" (CCI) program. This program aims to realize the full potential of the long-term global Earth Observation archives from satellites as a significant and timely contribution to the ECV databases for climate modellers and researchers. Sea level is one of the listed ECVs of the CCI program. During the first phase (2010-2013) of the sea level CCI project (SL_cci), the first version of the ECV over the 1993-2010 time span was produced and distributed to the user community. Details of the production and validation protocol of this ECV are described in Ablain et al. (2015).

Within the second phase of the project (2014-2017), the objective was not only to extend the length of the sea level record by additional 5 years (2010-2015) but also to provide a full reprocessing of the sea level ECV during the altimetry period thanks to the development and selection of new altimeter algorithms to improve the ECV accuracy, stability and homogeneity. The details of the orbit solutions, the geophysical corrections, the altimeter standards and processing algorithms selected for the production of this v2.0 ECV are fully described in Quartly et al. (2017).

This paper describes the SL_cci v2.0 ECV and presents some validation results obtained through different approaches. After a short description of input data and altimeter standards used in the production system (Sect. 2), a presentation of the v2.0 SL_cci products is provided in Sect. 3. The quality assessment of the ECV is described in Sect. 4. The consistency with the sea level records provided by other groups has been checked, and comparisons were also performed with in situ tide gauge measurements and combined Argo-based steric and GRACE-based barystatic sea level data. Additional validations based on a sea level budget closure approach and comparisons with the output from highresolution ocean models are also presented (Sect. 5). The sea level errors and uncertainties are discussed in Sect. 6 with respect to the GCOS requirements (GCOS, 2011). They correspond to the error levels to be met by the sea level record on different spatial and temporal scales (e.g. long-term evolution and inter-annual and annual signals). These requirements have been considered as a reference within the CCI program and especially when assessing the quality of the SL_cci ECV. The paper finishes with the discussion of perspectives on evolution of the sea level products.

\section{Input data and altimeter standards}

The estimation of the altimeter-based sea level is currently based on measurements from many satellite missions (spanning more than 20 years). The input data used for the production of the first version of the SL_cci ECV v1.1 were derived from TOPEX/Poseidon, Jason-1, Jason-2, ERS-1, ERS-2, GeoSat Follow-On (GFO) and Envisat satellites. The first three missions fly along the so-called "reference orbit", sampling the ocean between $66^{\circ} \mathrm{S}$ and $66^{\circ} \mathrm{N}$. The remaining missions have a higher orbital inclination, providing improved ocean sampling and giving near-complete coverage of the Arctic. A weakness of the v1.1 ECV is the limited number of satellite altimeters used in the production system. In particular, new altimeter missions (e.g., SARAL/AltiKa, CryoSat-2) have not been included when the temporal extensions of the dataset have been produced and the v1.1 sea level record is based on a single satellite (Jason-2) after the loss of Jason-1 in June 2013. It has affected the ECV in terms of reduced spatial coverage (no measurements north of $66^{\circ} \mathrm{N}$ ) and in terms of variance due to a deterioration of the sampling of the ocean. These elements have been improved in the SL_cci v2.0 ECV since new altimeter missions (SARAL/AltiKa and CryoSat-2) have been additionally included in the production system, covering the period January 1993 to December 2015 (see Fig. 1 of Quartly et al., 2017).

The ESA CCI objectives put strong emphasis on developing homogeneous datasets with long-term consistency, which necessitates not only stability for the duration of individual altimeter missions, but also great care in minimizing bias between missions. This has significantly impacted the SL_cci project since sea level estimation from altimetry re- 


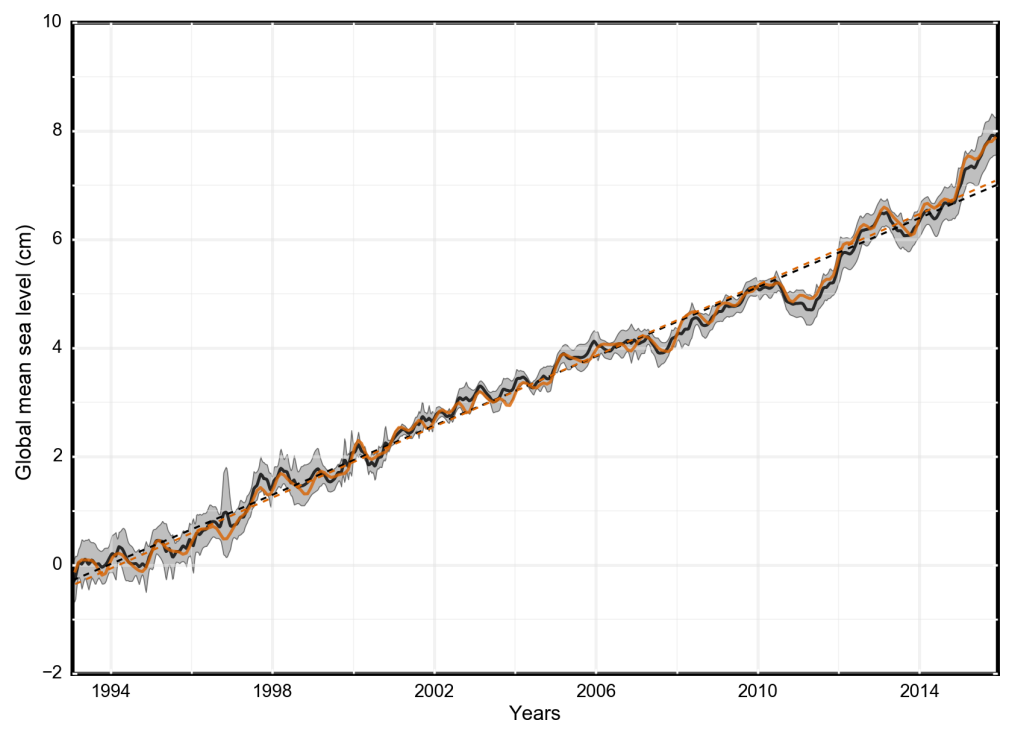

Figure 1. Comparison of the SL_cci v2.0 global MSL (solid orange line) with the associated linear trend (dashed orange line) and the ensemble mean (solid black line) of the global MSL derived from different groups (DUACS DT2014, CSIRO, Colorado University, GSFC and NOAA) with the associated linear trend (dashed black line) during the period 1993-2015. During this period, the trend of the SL_cci global MSL amounts to $3.3 \pm 0.5 \mathrm{~mm} \mathrm{yr}^{-1}$ with a $90 \%$ confidence interval. The grey envelope shows $1.65 \mathrm{SD}$ of the ensemble mean $(90 \%$ confidence interval). The seasonal variations have been removed and an offset has been introduced so that the mean of the 1993 data is set to zero.

quires implementation of many different algorithms to provide corrections for orbits, atmospheric delays, tides and sea surface effects (e.g. Fu and Cazenave, 2000; Ablain et al., 2017; Escudier et al., 2017). Many different solutions have been adopted over the past decades for each altimeter standard, either developed by the SL_cci consortium or provided by external projects. To select the most appropriate algorithm to ensure homogeneity and stability of the sea level product, the SL_cci project held an Algorithm Selection Meeting in November 2015, during which the latest algorithms were independently evaluated and validated according to a formal validation protocol. The associated round robin data packages (RRDPs) showing the impact of each standard and the output of the meeting are available on the SL_cci website (http://www.esa-sealevel-cci.org/PublicDocuments) (Legeais and the ESA SL_cci team, 2016c), with a synopsis of the comparisons given in Quartly et al. (2017). Many of the applied corrections have been revised, in particular modelled orbits due to time-variable gravity (Rudenko et al., 2014, 2016; Couhert et al., 2015), satellite attitude, macromodels and tropospheric correction models for DORIS observations (Rudenko et al., 2017), modifications to the wet tropospheric correction based on combined GNSS and radiometer datasets (Fernandes et al., 2015), and the latest changes in ocean tide (FES2014) and pole tide (Desai et al., 2015).

\section{Description of the SL_cci v2.0 ECV}

The SL_cci v2.0 products are based on multi-mission sea level measurements. They are provided as a database of different elements, referenced with the following DOI: https://doi.org/10.5270/esa-sea_level_cci-1993_2015v_2.0-201612. The different products available for the users are the following:

1. The Fundamental Climate Data Record (FCDR) is the along-track sea level anomaly (SLA) derived from the nine altimeter missions, available at $1 \mathrm{~Hz}$ resolution corresponding to a ground distance of $\sim 7 \mathrm{~km}$. The files include a quality control indicator to remove spurious measurements and all altimeter standards applied in the SLA calculation (geophysical corrections, mean sea surface). In addition, information derived from the intermission sea level cross-calibration is provided in order to remove global and regional biases and to homogenize long-spatial-scale errors (e.g. due to orbit calculation). In addition to the FCDRs, gridded values of the altimeter dynamic atmospheric correction (DAC) forced by the ERA Interim reanalysis (Carrère et al., 2016) used for the production of the SL_cci products (including the SLA) are also available to the users. This may be of interest when comparing altimeter data with in situ measurements from tide gauges since both datasets should be corrected for the same atmospheric corrections.

2. The SL_cci ECV consists of monthly gridded time series (January 1993-December 2015) of multi-mission 


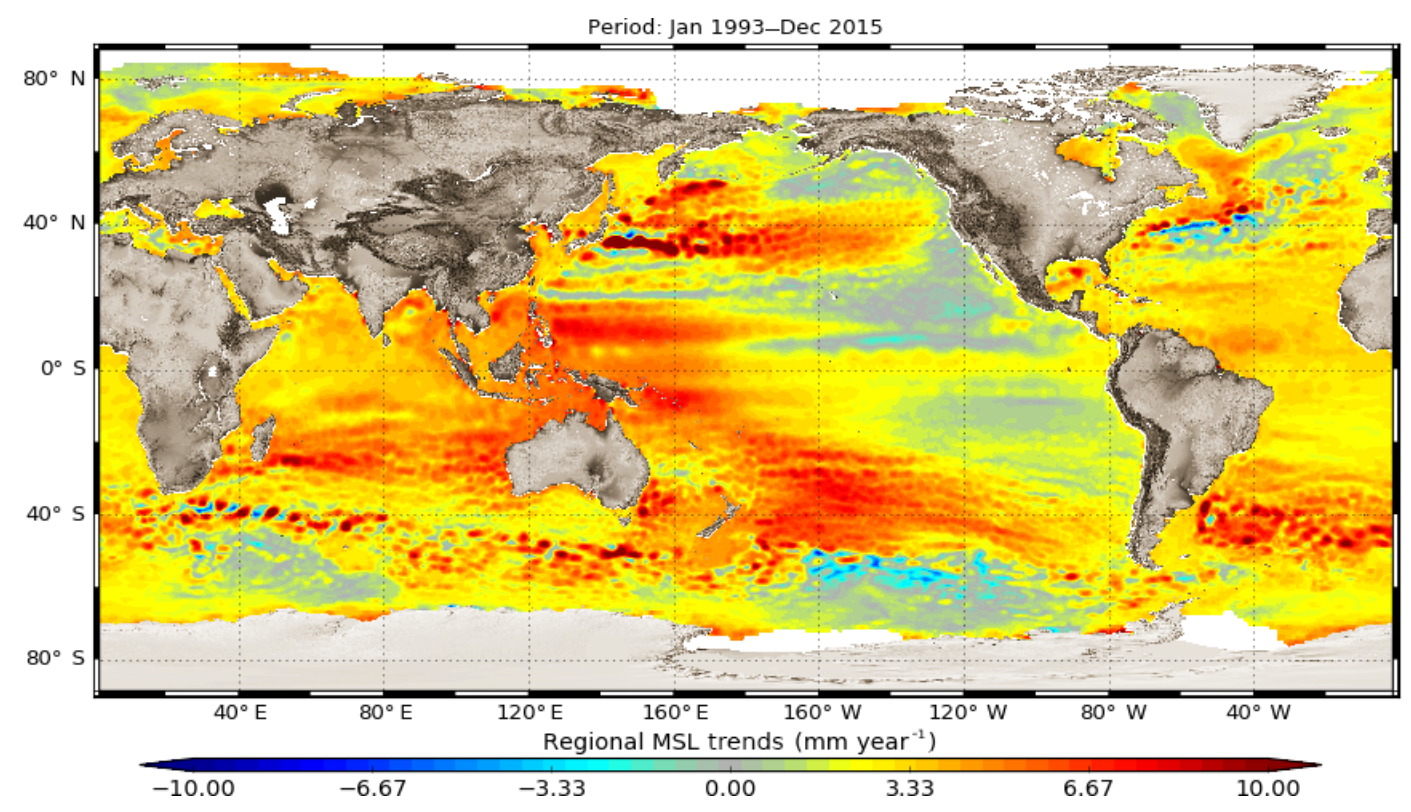

Figure 2. Regional MSL trend (from SL_cci v2.0 ECV) during the period 1993-2015.

merged SLA at a spatial resolution of $0.25^{\circ}$. The SL_cci v2.0 ECV has been generated thanks to the CNES/CLS DUACS production system with the same procedures as for the previous version v1.1 (Ablain et al., 2015) (except that the grids have been shifted by half a pixel in v2.0). The main processing steps (developed in Ablain and Legeais, 2014) are as follows: (i) acquire and preprocess data, (ii) perform input check and quality control, inter-calibrate and unify the multi-satellite measurements and (iii) generate along-track and gridded merged products (based on a monthly optimal interpolation). A land-sea mask derived from the LandCover_cci project has been applied to all sea level grids. The longterm stability and large-scale changes of the SL_cci v2.0 dataset are built upon the records from missions in the reference orbit (TOPEX/Poseidon, Jason-1 and Jason-2 for that period). All these satellites, called reference missions, have the same 9.92-day orbital cycle at high altitude $(1336 \mathrm{~km})$, making satellite trajectories less sensitive to higher-order terms of the Earth's gravity field. Data from the other missions (also called complementary missions) that contribute to improving the sampling of mesoscale processes provide the high-latitude coverage and increase the product accuracy. More details on the SL_cci ECV processing are provided in Quartly et al. (2017) and additional general information on the altimeter data processing can be found in Pujol et al. (2016).

3. Ocean indicators are derived from the SL_cci ECV: GMSL time series (Fig. 1), regional grids of sea level trends (Fig. 2), and maps of the amplitude and phase of the annual (Fig. 3) and semi-annual signals during the period available.

4. In addition to the SL_cci ECV, the along-track intercalibrated sea level measurements of each mission (level 3 of the altimeter processing) are also available to users. The included information is the filtered and subsampled valid SLA, where long wavelength biases have been removed to make observed sea level measurements homogeneous and consistent between the nine altimeter missions. These data are the input measurements of the mapping procedure and can be used for data assimilation in ocean models, for instance.

5. Improving the quality of the Arctic sea level record has also been one of the key regional foci during the SL_cci project. This has led to two new Arctic sea level records available to the users. The CLS/PML product is based on improved waveform classification and retracking, applied on the Envisat and SARAL/AltiKa missions (Poisson et al., 2017). DTU/TUM proposed two versions of their Arctic sea level product, both derived from the ERS-1 and 2, Envisat, and CryoSat-2 missions: one is based on an empirical altimeter retracking and the second is based on the ALES + retracking (Passaro et al., 2017). Results of the validation and comparison of these products can be found in Carret et al. (2016).

\section{Quality assessment on climate scales}

The validation of the reprocessed SL_cci v2.0 ECV has been carried out over different spatial and temporal scales. 


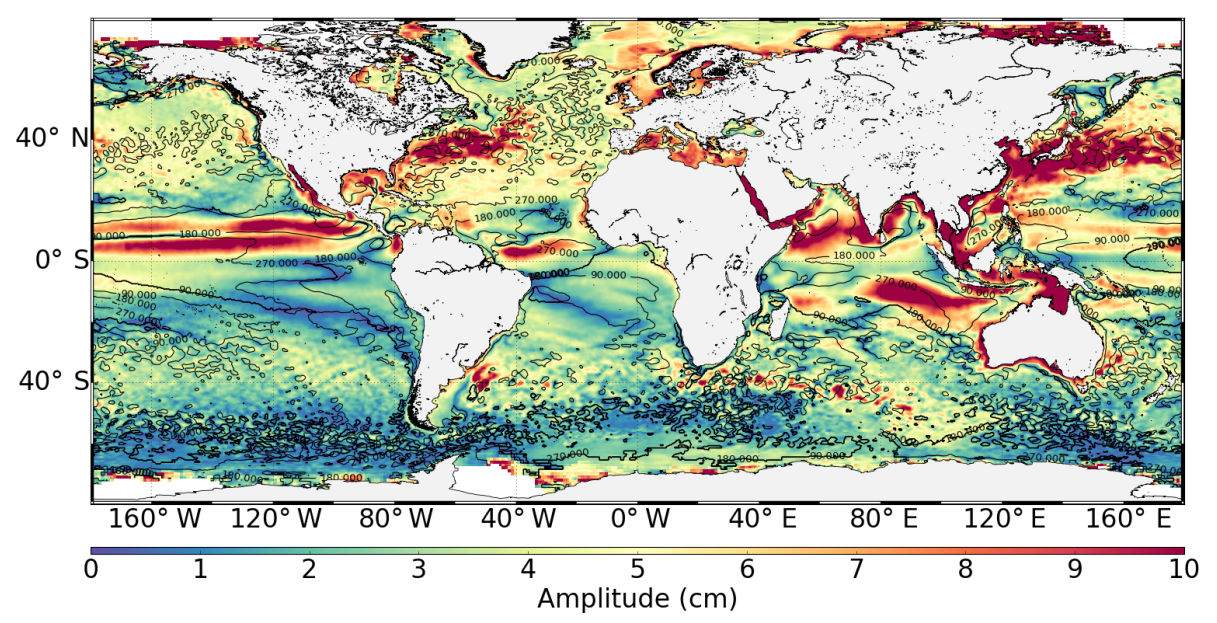

Figure 3. Global amplitude (coloured contours, between 0 and $10 \mathrm{~cm}$ ) and phase (superimposed black isolines, between 0 and $360^{\circ}$ ) of the annual cycle of the SL_cci ECV v2.0 during 1993-2015.

\subsection{Long-term GMSL evolution}

The GMSL trend derived from the SL_cci ECV v2.0 during the period $1993-2015$ amounts to $3.3 \pm 0.5 \mathrm{~mm} \mathrm{yr}^{-1}$ with a confidence interval of $90 \%$ (1.65 SD). The GMSL trend derived from the reprocessed dataset is the same as the one derived from the ensemble mean of GMSL from other altimeter groups (Fig. 1). When compared with the previous v1.1 $\mathrm{ECV}$, no trend difference is observed during the common reduced period (1993-2014) (Fig. 4). However, over decadal timescales, the v2.0 GMSL trends are significantly different to those from v1.1 (by $-0.2 \mathrm{~mm} \mathrm{yr}^{-1}$ during 1993-2003 and $+0.2 \mathrm{~mm} \mathrm{yr}^{-1}$ during 2004-2014, see Fig. 4). This is mainly due to the use of the level 2 GNSS Path Delay Plus (GPD+) wet troposphere correction (Fernandes and Lázaro, 2016) for all missions in the v2.0 (except for GFO) (see Quartly et al., 2017 for more details). This is because all radiometers used in GPD+ V2.0 have been calibrated against the Special Sensor Microwave Imager and the Special Sensor Microwave Imager/Sounder, due to their known stability and independent calibration (Wentz, 2013).

For the v2.0 GMSL, the same trend of $3.3 \mathrm{~mm} \mathrm{yr}^{-1}$ is found for the 1993-2003 and 2005-2015 altimetry decades, indicating a steady rise of the GMSL. However, several recent studies using different approaches suggest that an instrumental drift has affected the TOPEX-A altimeter measurements during 1993-1998 (Valladeau et al., 2012; Watson et al., 2015; Dieng et al., 2017; Beckley et al., 2017). The instrumental drift of the TOPEX-A altimeter has long been known (Hayne and Handcock, 1998), leading to the switch early 1999 to the redundant TOPEX-B altimeter. But until recently, it was considered that the TOPEX-A drift had minimal impact on the GMSL. Based on a comparison between TOPEX-A sea level and tide gauge data, Valladeau et al. (2012) challenged this conclusion but did not quantify this effect on the GMSL. More recently, three studies have

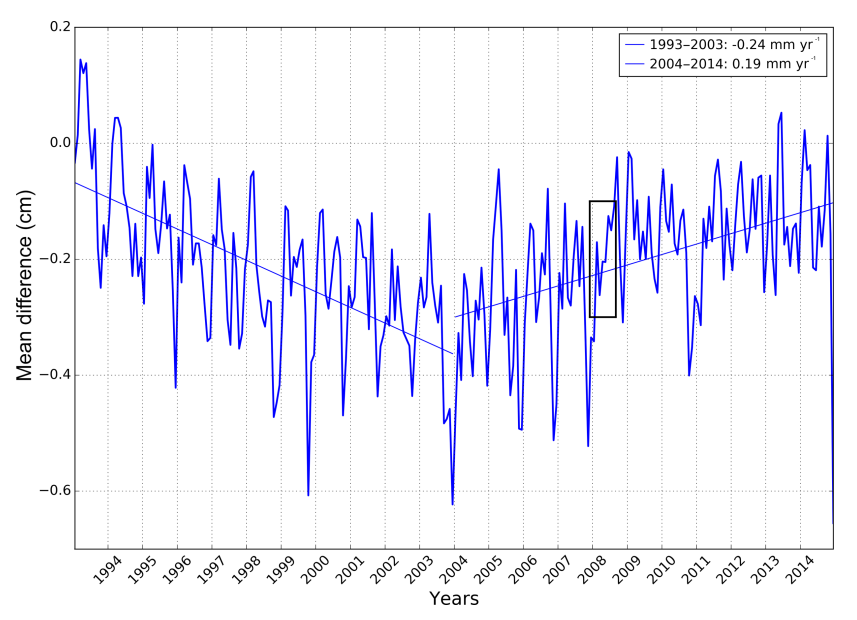

Figure 4. Global mean sea level differences between the SL_cci ECV v2.0 and v1.1. The trends are indicated for the periods 19932003 and 2004-2014. No trend difference is observed between ECV v1.1 and v2.0 during their common period 1993-2014 (not shown). A jump is observed in mid-2008, illustrating the anomaly of ECV v1.1 that has been corrected in ECV v2.0 (see the black box).

attempted to quantify the effect of the TOPEX-A drift on the GMSL trend over the period January 1993-December 1998. Watson et al. (2015) compared altimetry-based sea level with vertical land motion-corrected tide gauge data and estimated a TOPEX-A drift correction to the 1993-1998 GMSL trend in the range $0.9 \pm 0.5$ to $1.5 \pm 0.5 \mathrm{mmyr}^{-1}$, with $1.5 \mathrm{~mm} \mathrm{yr}^{-1}$ being the preferred value. Using a sea level budget approach, Dieng et al. (2017) also estimated the TOPEXA drift correction to $1.5 \pm 0.5 \mathrm{~mm} \mathrm{yr}^{-1}$ for $1993-1998$. Another approach was followed by Beckley et al. (2017), consisting of suppressing the so-called "internal calibrationmode" range correction, included in the TOPEX-A "net instrument" correction and considered as suspect. Account- 
ing for the TOPEX-A instrumental correction for the first 6 years of the altimetry dataset, these studies provided a revised GMSL time series that slightly reduces the average GMSL rise over the altimetry era (from 3.3 to $3.0 \mathrm{~mm} \mathrm{yr}^{-1}$ ), but shows clear acceleration over 1993-present. Using the corrected GMSL time series, Dieng et al. (2017) and Chen et al. (2017) found improved closure of the sea level budget compared to the uncorrected data.

In this paper, no TOPEX-A drift correction has been applied on the dataset available for the users as there is not yet consensus on the best approach to estimate it. However, ongoing work involving space agencies (National Aeronautics and Space Administration - NASA - and Centre National d' Etudes Spatiales - CNES) together with scientific teams should provide guidance and recommendations about this issue in the near future. As far as the SL_cci project is concerned, a corrected GMSL time series will be delivered to users in due time.

\subsection{Inter-annual signals}

The mean differences between the SL_cci v2.0 and SL_cci v1.1 are related to the different mean sea surface (MSS) used in both dataset (DTU15 and DTU10 respectively, see Quartly et al., 2017). On an inter-annual timescale, differences arise because of different mean reference periods used to compute the MSS (the period during which sea surface height measurements have been averaged). The reference period of the MSS DTU10 is 1993-2008 (15 years) whereas it is 19932012 (20 years) for the MSS DTU15. This is of major importance in the context of data assimilation in ocean models (Stammer and Griffies, 2017). Users interested in changing the reference period of the dataset can refer to the procedure described in annex A of Pujol et al. (2016). In addition to the reference period of the MSS, it is worth noting that a convention has been applied on the v2.0 sea level grids so that the averaged sea level during year 1993 is set to zero.

In the v1.1 SL_cci ECV, a $1 \mathrm{~mm}$ jump was found in the GMSL around mid-2008 (not shown). It is related to irregularities present in the Jason-1 radiometer data used to compute the GPD+ wet troposphere correction, which are enhanced near the coast using the methodology described in Brown (2010). The corresponding error was accounted for via a GMSL bias between Jason-1 and Jason-2 and was propagated to Jason- 2 over the whole period. This error has been reduced in the v2.0 reprocessing and is therefore partly visible in the v2.0-v1.1 GMSL differences shown in Fig. 4.

The inter-annual variations of the SL_cci v2.0 GMSL remain in the envelope of the ensemble mean of the GMSL data from other groups (Fig. 1), which illustrates the homogeneity of the processing of the satellite measurements on these timescales. More validation details on inter-annual timescales are provided by comparison with other GMSL products (Sect. 5).

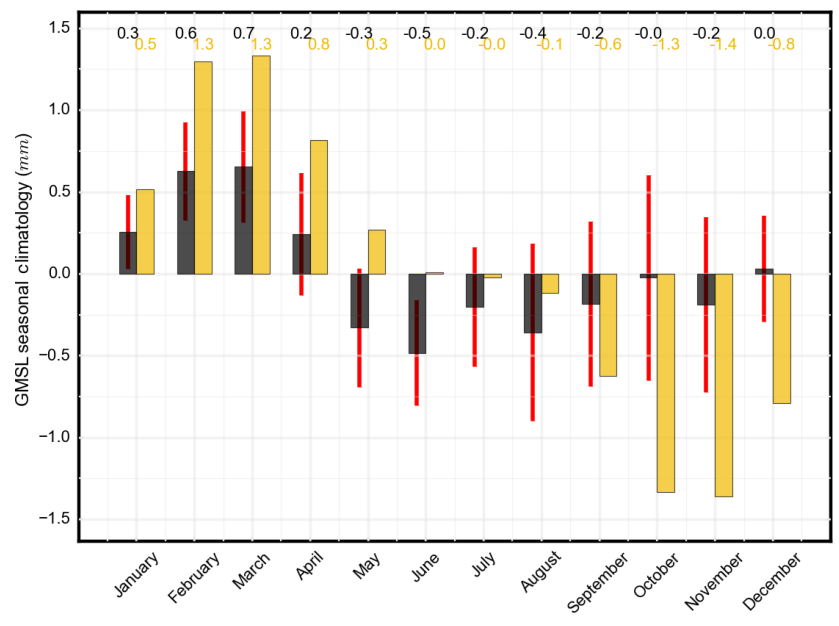

Figure 5. SL_cci v2.0 global MSL monthly climatology (yellow) compared with the ensemble mean (black) of the monthly climatology derived from different groups (DUACS DT2014, CSIRO, Colorado University, GSFC and NOAA); the red bars show the associated SD. The period considered for the monthly average is 19932015.

\subsection{Seasonal cycle}

The regional amplitude and phase of the annual cycle of the sea level ECV v2.0 are illustrated in Fig. 3. A number of factors affect the amplitude and phase of the mean seasonal cycle at a point: solar elevation, cloud cover, mixed layer depth and riverine input. The amplitude of the seasonal cycle is much greater in the Northern Hemisphere, especially for regions affected by the Gulf Stream and Kuroshio Current, whereas the deep waters associated with the BrazilFalklands Confluence and the Agulhas Current show much weaker seasonality, with the expanse of the Antarctic Circumpolar Current showing little change. A more detailed analysis of the phase of the annual cycle (not shown) reveals that the North Atlantic and North Pacific north of $20^{\circ} \mathrm{N}$ generally peak in September-October, whereas the oceans south of $20^{\circ} \mathrm{S}$ peak in February-April. A much more complex pattern is found in the tropical belt, with our analysis confirming the work of Chen and Quartly (2005), who found October peaks for parts of the southern tropical Indian Ocean and for a region stretching from the Amazon to Africa. Chen and Quartly (2005) identified several amphidromic points in these regions, several of which are similarly located in the analysis of the longer SL_cci v2.0 dataset. The tropical Pacific remains hard to interpret because the long-term variations associated with ENSO may affect the "normal" seasonal cycle for that region. The assessment of the GMSL annual cycle from the v2.0 ECV is based on the monthly climatology during the period of the sea level record (see Fig. 5). The resulting signal displays a smoother annual cycle than the one derived from the ensemble mean of the monthly climatology derived from other products. Given the expected 
shape of the sea level annual cycle (Chen et al., 1998; Legeais et al., 2016a) and the long length of the record (that filters out the potential peaks during this period), this suggests an improved estimate of the seasonal signal in the reprocessed SL_cci ECV. Compared with the v1.1 ECV, a small difference is observed in terms of the amplitude $(1 \mathrm{~mm})$. It is assessed by comparison with tide gauge measurements (Valladeau et al., 2012). The amplitude of the annual cycle of the sea level difference computed against predominantly coastal in situ data reaches $2.4 \mathrm{~mm}$ with the $\mathrm{v} 1.1 \mathrm{ECV}$ and is reduced to $1.6 \mathrm{~mm}$ with the $\mathrm{v} 2.0 \mathrm{ECV}$, suggesting that the annual signal is better retrieved with the reprocessed dataset. This observed difference is related to the changes in the level 2 altimeter standards involved in the ECV production, the main contributors being the orbit solutions (Couhert et al., 2015; Rudenko et al., 2017) and the GPD+ wet troposphere correction (Fernandes and Lázaro, 2016) used for the different altimeter missions (Quartly et al., 2017). The new pole tide correction (Desai et al., 2015) also affects the amplitude of the annual cycle. As illustrated by the Taylor diagram (Taylor, 2001) in Fig. 6, the comparison with external independent data confirms that it leads to an improved sea level estimation compared with the v1.1 ECV (Wahr, 1985). This figure compares the amplitude of the annual cycle of the Envisat and Jason-1 sea level computed with both pole tide corrections, with the sum of the steric dynamic height anomalies derived from the Argo in situ network and the GRACE ocean mass contribution (grey dot on the $x$ axis). An increased correlation between both datasets and a reduced variance of the difference is obtained with the new correction.

\subsection{Regional sea level trends}

The regional sea level trends during 1993-2015 (Fig. 2) can deviate considerably from the global mean (typical values range spatially between -5 and $+5 \mathrm{~mm} \mathrm{yr}^{-1}$ around the $3 \mathrm{~mm} \mathrm{yr}^{-1}$ global estimate). Over this 23 -year-long time span, this is essentially due to non-uniform thermal expansion (Stammer et al., 2013), in response to natural internal climate variability (Meyssignac et al., 2012; Palanisamy et al., 2015a, b; Han et al., 2017). However, in some regions, like the Southern Ocean, an anthropogenically forced signal is already probably emerging. The regional sea level trends during 1993-2015 exhibit large-scale variations with regions of almost no sea level change and others with amplitudes reaching up to $+(8-10) \mathrm{mm} \mathrm{yr}^{-1}$ such as in the western tropical Pacific Ocean (Fig. 2). In this area, trends are mainly of thermosteric origin (Legeais et al., 2016b; Meyssignac et al., 2017) in response to increased easterly winds during the last 2 decades associated with the decreasing Interdecadal Pacific Oscillation (IPO)/Pacific Decadal Oscillation (e.g. Merrifield et al., 2012; Palanisamy et al., 2015a; Rietbroek et al., 2016).

The regional trend differences between the SL_cci v2.0 and v1.1 display values ranging between -1.5 and $+1.5 \mathrm{~mm} \mathrm{yr}^{-1}$ (Fig. 7). The large-scale differences are ex-

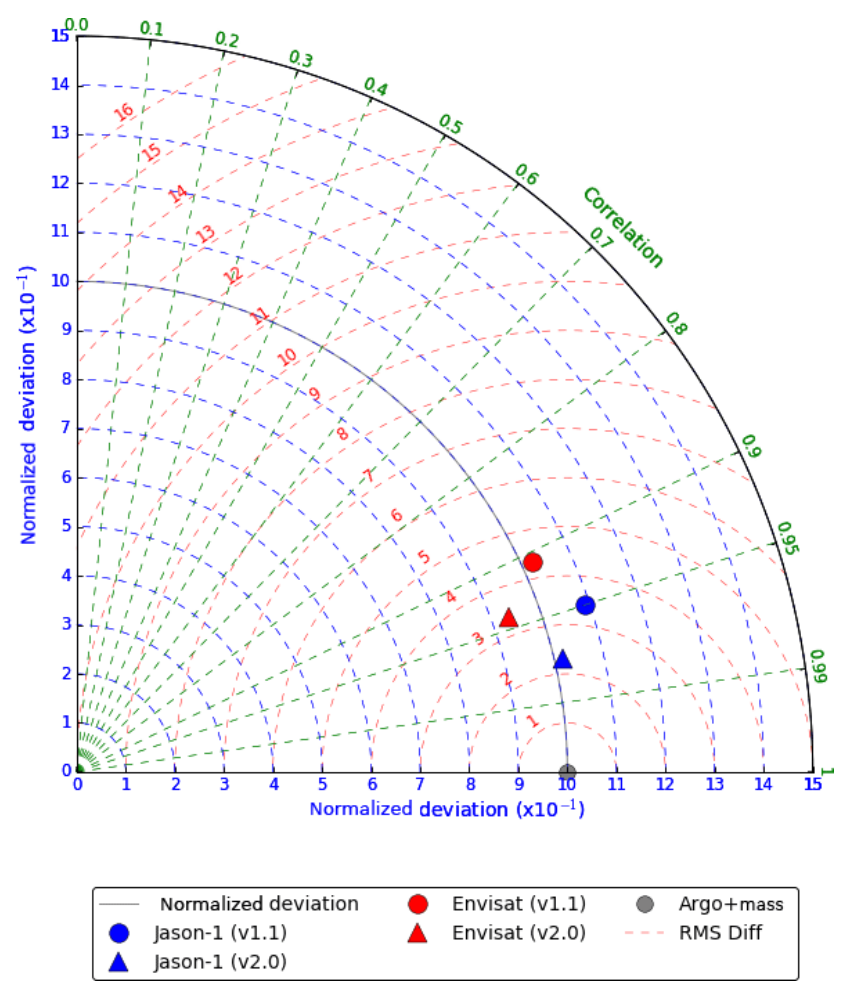

Figure 6. Taylor diagram of the annual signal of the Envisat (in red) and Jason-1 (in blue) sea level anomalies (2005-2012) calculated considering the pole tide corrections derived both by Wahr (1985) (circle, used in ECV v1.1) and by Desai (2015) (triangle). They are compared with the independent sea level estimation (grey dot) derived from the in situ Argo dynamic heights anomalies (referenced to $900 \mathrm{dbar}$ ) and the GRACE ocean mass contribution (GRGS RL03v1).

plained by the differences of altimeter standards used in both versions, and the orbit solutions are the main contributor (see more details in Quartly et al., 2017). The small-scale differences observed over the global ocean are related to the difference in the satellite constellation between both versions of the ECV. Indeed, CryoSat-2 and SARAL/AltiKa missions are used after 2012 in v2.0 and were not included in v1.1. This means that sampling of the ocean is not the same in both datasets: the empty interleaved spaces between Jason-2 tracks in the v1.1 ECV have been sampled with CryoSat-2 and SARAL/AltiKa in the v2.0 ECV, which directly affects the trend differences, especially in the regions of high ocean variability.

\subsection{Mesoscale signals}

The SLA variance provides an estimate of the sea level variability referenced to the mean sea surface used for the SLA calculation. The global SLA variance differences between SL_cci v2.0 and v1.1 time series are on average $+3 \mathrm{~cm}^{2}$ over the common period, indicating that more variability is ob- 

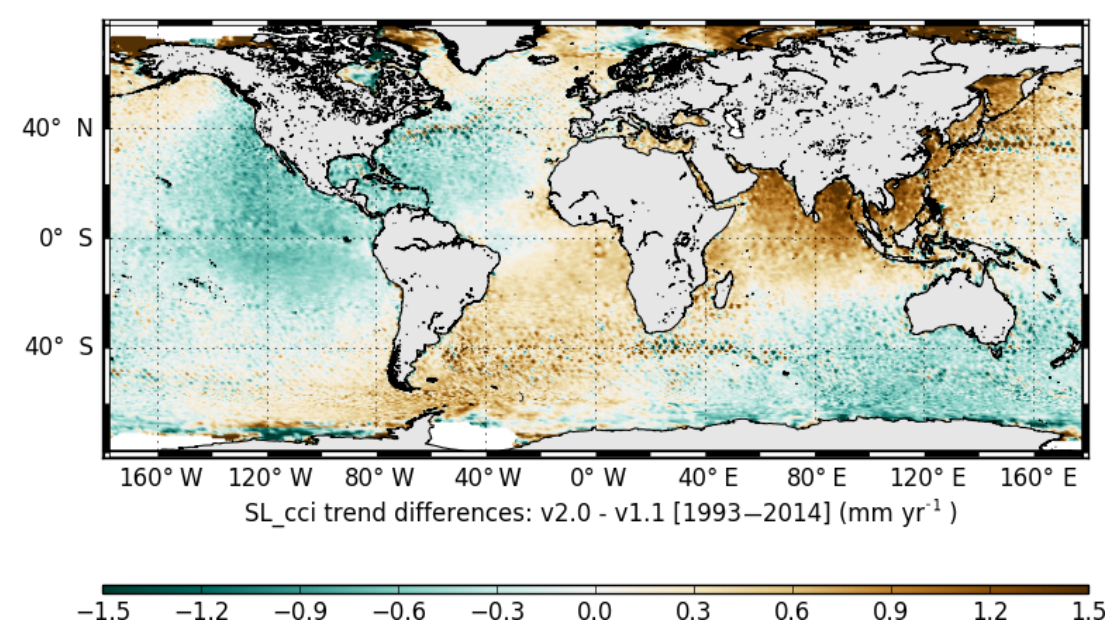

Figure 7. Regional mean sea level trend differences between the SL_cci ECV v2.0 and v1.1 during 1993-2014.
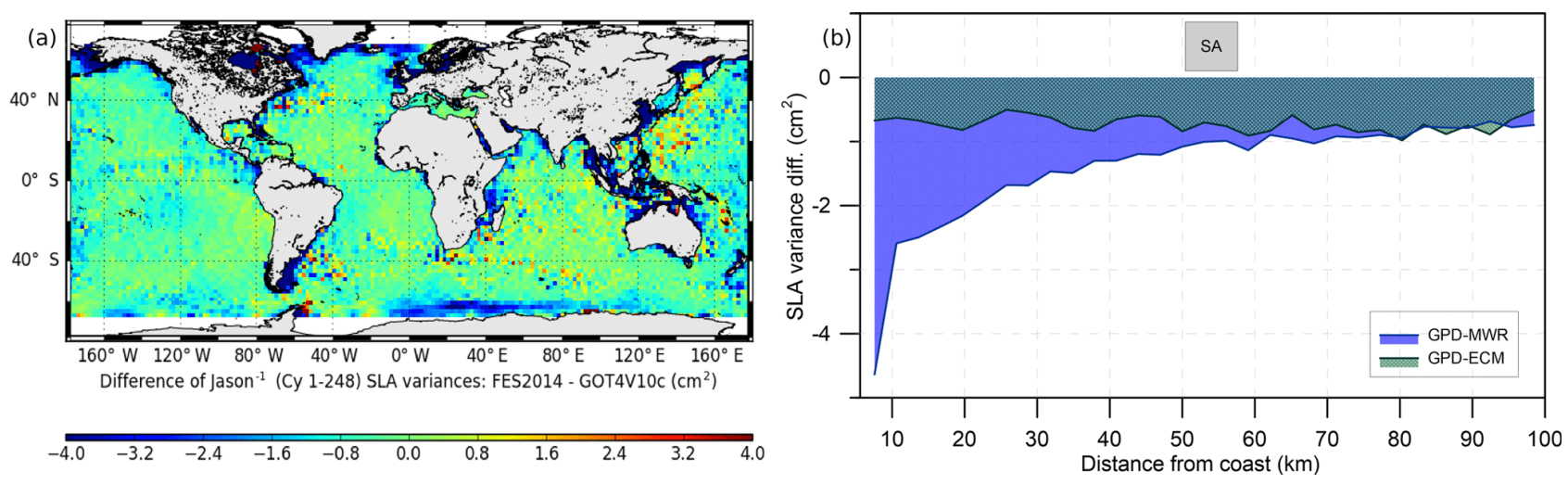

Figure 8. (a) Sea level variance differences for Jason-1 cycles 1-248 (2002-2008) using FES2014 and GOT4.10c ocean tide corrections successively. (b) SARAL/AltiKa sea level variance difference calculated with different wet troposphere corrections (green compares GPD+ with ECMWF operational model and purple with the initial version of the radiometer correction) as a function of the coastal distance.

served in the reprocessed ECV (even when removing the seasonal cycle). This change in the SLA variance is explained by several factors: inclusion of new missions (CryoSat-2 and SARAL/AltiKa) in the v2.0 ECV, leading to an improved mesoscale estimation and allowing better coverage of the ocean at high latitudes; use of the FES2014 ocean tide model (instead of the GOT4.8) for all altimeter missions, providing a reduced sea level variance in many coastal and shelf areas, as well as at high latitudes (Fig. 8a); and use of the GPD+ wet troposphere correction (Fernandes and Lázaro, 2016), leading to improved sea level variance estimation in coastal regions for most altimeter missions compared with the previous non-calibrated version (Fernandes et. al., 2015) and to other wet troposphere correction datasets (see Fig. 8b for the example of the SARAL/AltiKa mission). Finally, the updated sea-state bias correction used for some missions (such as Envisat) also contributes to better retrieval of mesoscale signals. The reader should refer to Quartly et al. (2017) for the details of the aforementioned corrections.

\section{Sea level budget closure and comparison with model outputs}

Different types of external validations of the SL_cci v2.0 products have been investigated. They are briefly described below.

\subsection{Global mean sea level budget closure}

Closure of the global mean sea level budget implies that

$\Delta \operatorname{GMSL}(t)=[\Delta M \operatorname{Ocean}(t)+\Delta \operatorname{SSL}(t)]$,

where $\Delta$ means change of a given variable with time $t$; $\Delta M$ Ocean $(t)$ and $\Delta \operatorname{SSL}(t)$ are time-variable ocean mass and steric sea level components $(\operatorname{SSL}(t)$ being the depthintegrated change in seawater density due to ocean temperature $T$ and salinity $S$ variations). 


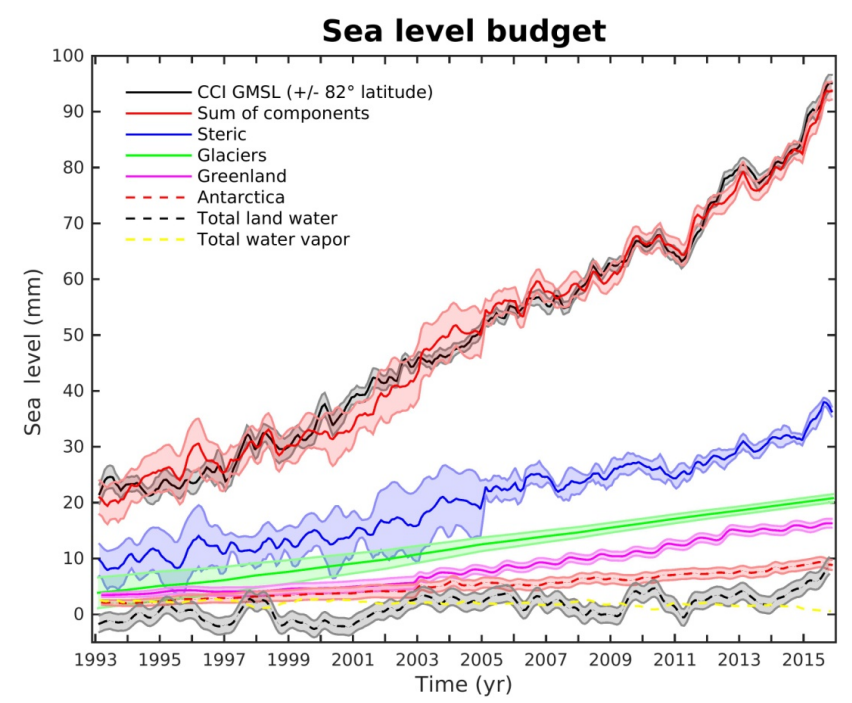

Figure 9. Sea level budget using the SL_cci v2.0 GMSL time series (adapted from Dieng et al., 2017). The $1.5 \mathrm{~mm} \mathrm{yr}^{-1}$ correction supposed to represent the TOPEX-A drift has been applied (specifically in this figure) to the GMSL time series for 1993-1998 as discussed in Sect. 4.1 (see Dieng et al., 2017 for details).

Water mass conservation in the climate system implies the following:

$$
\begin{aligned}
\Delta M \operatorname{OOcean}(t)= & -[\Delta M \operatorname{Glaciers}(t)+\Delta M \operatorname{Greenland}(t) \\
& +\Delta M \operatorname{Antarct.}(t)+\Delta M \operatorname{LWS}(t) \\
& +\Delta M \operatorname{AtmWV}(t) \\
& + \text { missing mass terms and errors }],
\end{aligned}
$$

where the $\Delta M(t)$ terms on the right-hand side refer to changes in mean glacier, Greenland and Antarctic mass balances, land water storage (LWS) and atmospheric water vapour (AtmWV).

We have investigated to what extent Eq. (1) is verified using the SL_cci v2.0 GMSL and different datasets for the ocean mass and steric components. The various contributions to the GMSL are summed to derive a "synthetic" global mean sea level. Consistency of the different products is evaluated and an error assessment study is performed. The synthetic global mean sea level is further compared with the global mean CCI sea level (both in terms of time series and trends).

We have considered the whole altimetry era (19932015) and used the various datasets considered in Dieng et al. (2017) to estimate the individual mass contributions (glaciers, ice sheets, stored land water, atmospheric water vapour and snow) of Eq. (1). Figure 9 shows the SL_cci v2.0 GMSL as well as the individual and sum of components over 1993-2015. The $1.5 \mathrm{~mm} \mathrm{yr}^{-1}$ correction supposed to represent the TOPEX-A drift has been applied to the GMSL time series for 1993-1998 specifically in this figure as discussed in Sect. 4.1; see Dieng et al. (2017) for details.

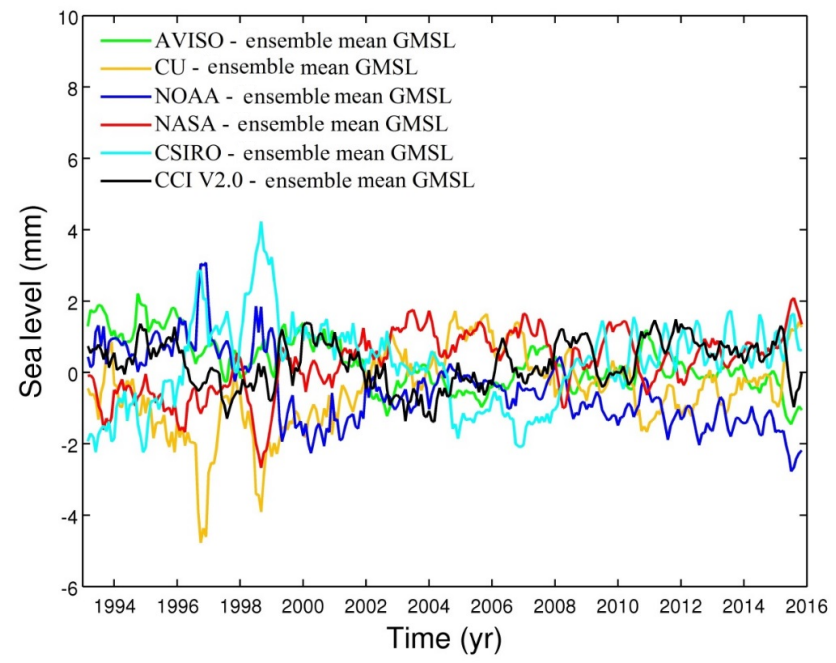

Figure 10. Differences between individual GMSL time series and ensemble mean GMSL (average of the 6 products) over January 1993-December 2015 (adapted from Dieng et al., 2017).

We have also used the SL_cci v2.0 time series as well as additional GMSL products provided by other groups (DUACS DT2014 distributed by CMEMS - previously AVISO University of Colorado, NOAA, NASA/GSFC and CSIRO) to compute the differences between each individual GMSL time series and the ensemble mean GMSL over 1993-2015. Both residual trend and RMS have been estimated. These are gathered in Table 1. We note that in terms of trend, all GMSL time series are very close, residual trends ranging from -0.11 to $+0.08 \mathrm{~mm} \mathrm{yr}^{-1}$ (all records used here are not corrected for the TOPEX-A instrumental drift). We conclude that looking solely at the trend does not allow us to provide significant assessment of the SL_cci v2.0 GMSL, although we note that the SL_cci v2.0 GMSL trend is one of the closest to the ensemble mean trend (difference of $0.02 \mathrm{~mm} \mathrm{yr}^{-1}$ ). The situation looks more favourable in terms of RMS, the SL_cci v2.0 time series giving the smallest RMS of the differences $(0.69 \mathrm{~mm}$, Table 1 and Fig. 10$)$. In addition, the residual GMSL obtained with the Colorado University and the CSIRO records are quite different to the ensemble mean during 1996-1999, which is not the case with the SL_cci dataset. This confirms the relatively good quality of the SL_cci v2.0 ECV on inter-annual timescales compared to other products. As the altimeter processing performed by the different groups are not the same, this inter-comparison highlights the contribution of the data processing to the GMSL uncertainty.

\subsection{Comparison with ocean reanalyses}

Assessment of the SL_cci v2.0 ECV has been carried out via multi-model approach by comparing with ocean reanalyses (ORA hereafter) from ECMWF. The reference ocean re- 
Table 1. Trend and root mean square of the difference between individual GMSL time series and ensemble mean GMSL (mean of observed GMSL). Note that all GMSL records are not corrected for the TOPEX-A instrumental drift (see text).

\begin{tabular}{lrc}
\hline & $\begin{array}{r}\text { Trend }\left(\mathrm{mm} \mathrm{yr}^{-1}\right) \\
\text { Jan 1993-Dec 2015 }\end{array}$ & $\begin{array}{c}\text { RMS (mm) } \\
\text { Jan 1993-Dec 2015 }\end{array}$ \\
\hline AVISO - ensemble mean GMSL & -0.07 & 0.77 \\
CU - ensemble mean GMSL & 0.07 & 1.23 \\
NOAA - ensemble mean GMSL & -0.11 & 1.13 \\
NASA - ensemble mean GMSL & 0.08 & 0.91 \\
CSIRO - ensemble mean GMSL & 0.02 & 1.22 \\
CCI (v2.0) - ensemble mean GMSL & 0.02 & 0.69 \\
\hline
\end{tabular}

analysis product from ECMWF is the new ORAS5, which is closely related to the ORAP5 system (see Zuo et al., 2014 and Tietsche et al., 2015). ORAS5 is produced using the NEMO Ocean Model coupled to LIM2 sea ice model (Barnier et al., 2006). A series of observation types were assimilated in ORAS5 using NEMOVAR Ocean data assimilation system in its 3DVar FGAT (first guess at appropriate time) approach. Observations assimilated in ORAS5 include ensemble (EN4) in situ profiles, SLA from DUACS DT2014, sea surface temperature (SST) from HadSST2 and sea ice concentration (SIC) from OSTIA. It is worth noting that radar altimetry SLAs were not assimilated in ORAS5 outside of $50^{\circ} \mathrm{S}$ to $50^{\circ} \mathrm{N}$ domain, or in any coastal region with bathymetry less than $500 \mathrm{~m}$. Altimeter-derived GMSL variations were also assimilated for the satellite era using a freshwater constraint in ORAS5 (see Zuo et al., 2015). A few other ORAs from ECMWF with slightly different configurations from ORAS5 (see Table 2) were also used here in order to estimate climate signal uncertainties. The gridded SLA maps (MSLA) from the SL_cci v2.0 ECV and ORAs were interpolated onto the same regular $1^{\circ} \times 1^{\circ}$ grid with an optimized land-sea mask to facilitate inter-comparison. It is worth noting that the v1.1 ECV suffers from its imperfect land-sea mask, which makes the estimation of GMSL (and its seasonal cycles) non-trivial. As mentioned earlier, an adequate land-sea mask has been used in ECV v2.0.

Regional maps of MSL trends from the SL_cci v2.0 ECV were evaluated against the DUACS DT2014 and ORAs, with the results shown in Fig. 11a. Thanks to the inclusion of two additional altimetry missions (CryoSat-2 and SARAL/AltiKa), ECV v2.0 shows improved data coverage in the Arctic regions compared with ECV1.1, and a more pronounced positive trend in the Beaufort Sea. This is consistent with the ORAs and DUACS DT2014 results. This positive trend is visible both in ORAS5 and ORAS5-LW with relatively low uncertainty $\left( \pm 1.5 \mathrm{~mm} \mathrm{yr}^{-1}\right)$, suggesting a robust climate signal in the western Arctic Ocean (see Giles et al., 2012). The spatial patterns of large uncertainties are reasonably consistent between SL_cci ECVs and ORAS5 (Fig. 11b), considering that these uncertainties were estimated following very different approaches. The sea level
Table 2. Summary of the ORAs used for the SL_cci v2.0 ECV evaluation. DUACS DT2014 MSLA (Pujol et al., 2016) is now distributed by CMEMS (previously AVISO). ORAS5 is the ECMWF $0.25^{\circ}$ resolution ocean-sea ice reanalysis; ORAS5-LW is the ORAS5-equivalent low-resolution (ORCA1 grid, with approximately $1^{\circ}$ resolution, with meridional refinement at the Equator) reanalysis. Both ORAS5 and ORAS5-LW have five ensemble members, generated by a generic perturbation scheme (Zuo et al., 2017). SST stands for sea surface temperature, SIC for sea ice concentration and SLA for sea level anomaly.

\begin{tabular}{lllc}
\hline Description & Resolution & Assimilation & Period \\
\hline DUACS DT2014 & $0.25^{\circ} \times 0.25^{\circ}$ & - & $1993-2015$ \\
SL_cci ECV v1.1 & $0.25^{\circ} \times 0.25^{\circ}$ & - & $1993-2014$ \\
SL_cci ECV v2.0 & $0.25^{\circ} \times 0.25^{\circ}$ & - & $1993-2015$ \\
ORAS5 & $0.25^{\circ} \times 0.25^{\circ}$ & SST, SIC, T, S, SLA & $1993-2015$ \\
ORAS5-LW & $1^{\circ} \times 1^{\circ}$ & SST, SIC, T, S, SLA & $1975-2015$ \\
\hline
\end{tabular}

trend uncertainty in ECMWF ORAs is due to observation representativeness errors and forcing analysis errors in the ECMWF ocean data assimilation system (Zuo et al., 2017), while sea level trend errors from SL_cci are only associated with the formal error adjustment of the trends and are thus not representative of the total regional altimeter MSL trend uncertainty (see Sect. 6 for more details). Areas with large errors are normally associated with strong mesoscale eddy activities. Moderate sea level trend uncertainties $\left(\sim 1.2 \mathrm{~mm} \mathrm{yr}^{-1}\right)$ were also observed in the tropical Pacific and southern Indian Ocean for ECV1.1 and ECV v2.0. Compared with the SL_cci ECVs, ORAS5 is overconfident in its MSLA changes at most tropical and subtropical regions, but less confident in the Southern Ocean. An attribution study from ORAS5 reanalysis suggests that the mean sea level trend is dominated by the steric term while the mass variations are only important when considering the coastal regions (Fig. 11c). The increase in the sea level in the Beaufort Gyre is almost entirely due to halo-steric changes (steric changes due to salinity variations), which is consistent with the changes of Arctic circulation in the Beaufort Gyre (see the next paragraph) and the recent increase of freshwater there (Giles et al., 2012). The sharp front and reversing sea level trends signals in the North Atlantic suggest that the 
(a)

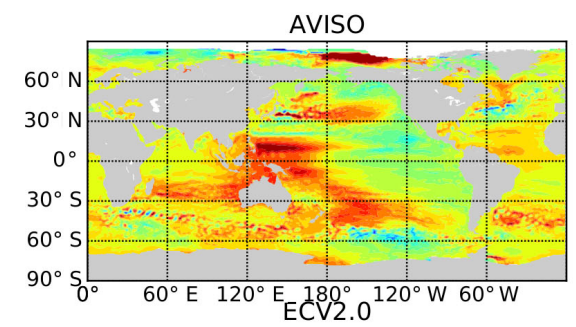

(b)
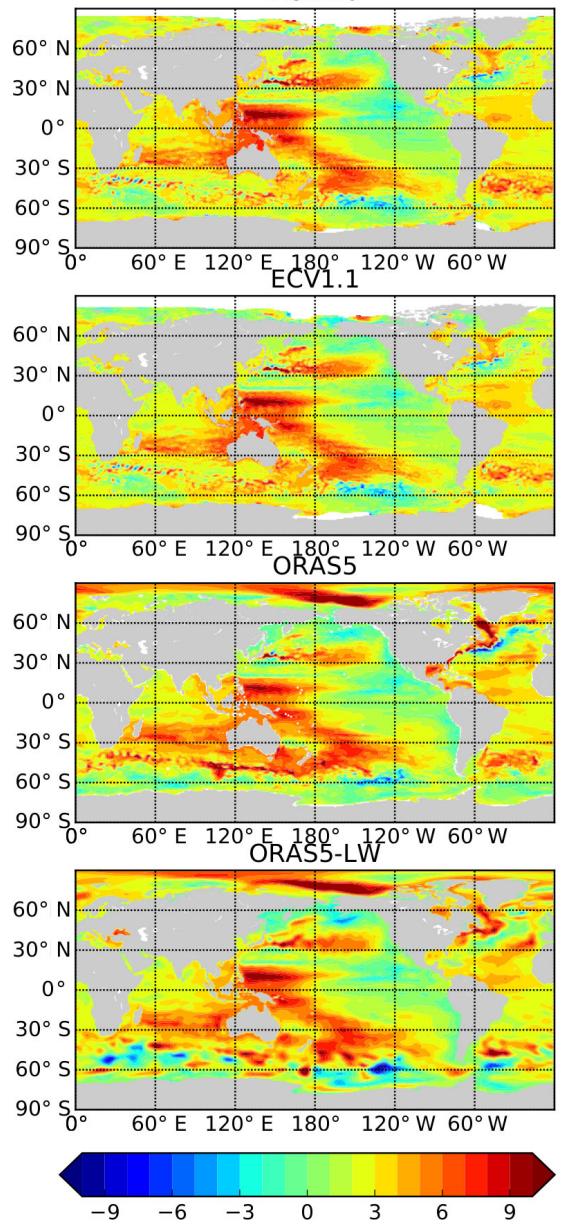

ECV 2.0
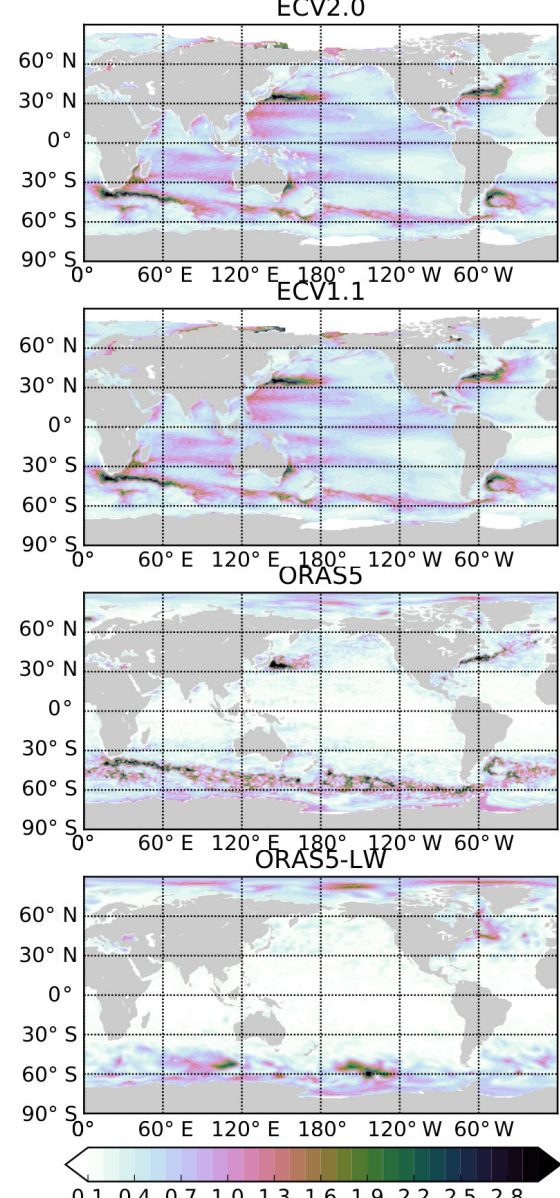

(c)
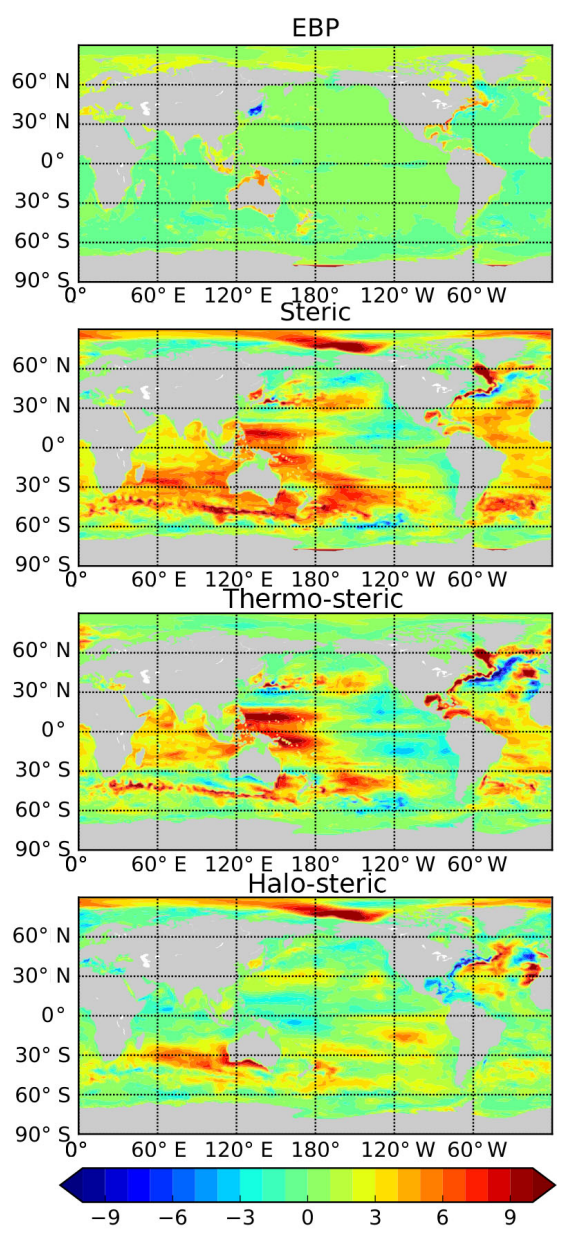

Figure 11. (a) Mean sea level trends (in $\mathrm{mm} \mathrm{yr}^{-1}$ ) and (b) uncertainties in DUACS DT2014, SL_cci ECV v2.0 and v1.1, ORAS5, and ORAS5-LW. MSL trends are computed using monthly mean sea level data from 1993-2014. Trend uncertainties have been provided as climate indicators with the ECV products and were estimated using ensemble spread from five ensemble members of ECMWF ORAs; (c) attributions of the MSL trends derived from ORAS5 as, from top to bottom, equivalent bottom pressure (EBP) mass variations, steric changes, and thermo-steric and halo-steric changes for the same period.

pathway of Gulf Stream extensions may be misrepresented in ORAS5, which is a common issue in ocean reanalysis.

\subsection{Comparison with the TOPAZ and NorESM models in the Arctic region}

The SL_cci v2.0 products for the high-latitude seas and Arctic Ocean are also compared with and assessed against complementary sea level fields derived from the TOPAZ data as- similation system and the Norwegian Earth System Model (NorESM) for the period 1993-2016. In the Sub-Polar Gyre the models and observations show smooth seasonal variability with comparable amplitudes of around $5-7 \mathrm{~cm}$ (see Fig. 12a). In addition, a trend of just below $+3 \mathrm{~mm} \mathrm{yr}^{-1}$ is found for the observations and the NorESM simulation, while it is slightly less for the TOPAZ reanalysis. In the Lofoten Basin the comparison shows that the amplitude of seasonal signals is slightly larger $(>10 \mathrm{~cm})$, while the trend in 

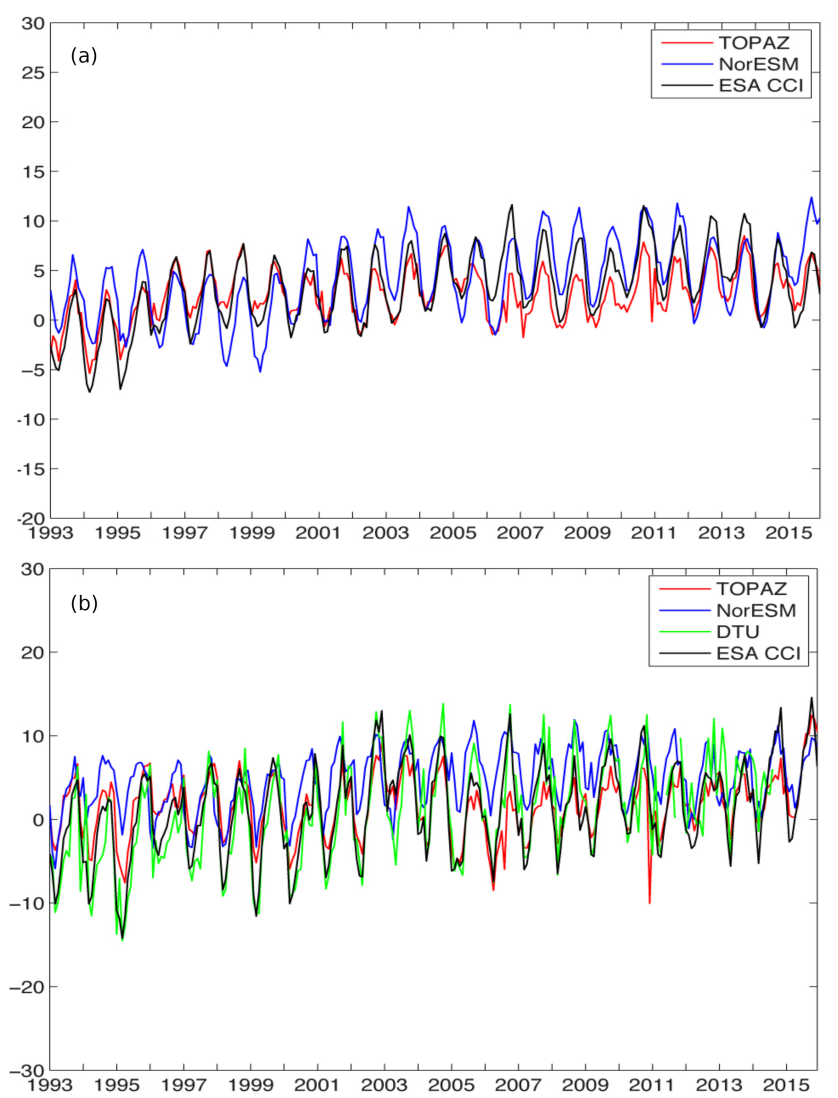

Figure 12. Seasonal to annual changes in sea level $\left(\mathrm{mm} \mathrm{yr}^{-1}\right)$ for the period 1993-2016 for the Sub-Polar Gyre (a) and the Lofoten Basin (b). For the Lofoten Basin the DTU-based sea level change is also displayed for the comparison. For both plots the vertical axis is in centimetres.

the SL_cci v2.0 observations is about $3 \mathrm{~mm} \mathrm{yr}^{-1}$ compared with about $1.5-2 \mathrm{~mm} \mathrm{yr}^{-1}$ for the model fields. These differences may result from the spatial pattern of the trend in the sea level rise which is more confined in the model fields than in the observations (see also Fig. 13).

In Fig. 13 the TOPAZ4 reanalyses fields are shown for the thermosteric and halosteric trends (upper) and the steric and total trends (lower). As noted in the ECMWF comparison (Fig. 11), the thermosteric trend in TOPAZ4 has little influence on the steric and total trends in the Beaufort Gyre. In contrast the positive trend in the sea level rise appears to fully emerge from the halosteric trend except on the Siberian Shelf where it is most likely connected with the bottom pressure and hence related to water mass accumulation on the shelf. The apparent freshening of the Beaufort Gyre is consistent with findings reported by Morison et al. (2012), who proposed that this occurred as a result of persistent changes in the pathways of Arctic freshwater.

In comparison to the SL_cci v2.0 trends depicted in the Arctic Ocean, the TOPAZ4 sea surface height trends display more distinct regional structures of sea level rise and decline.

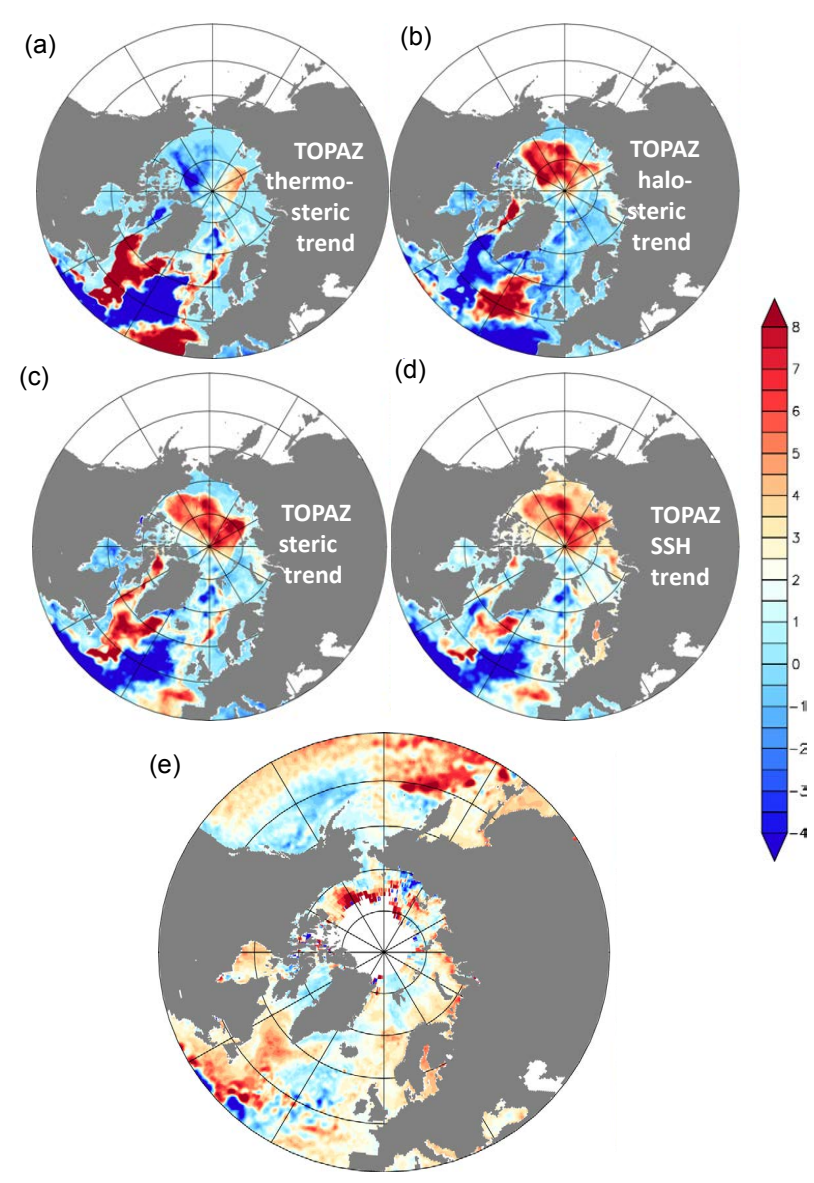

Figure 13. Contribution to the sea level trend $\left(\mathrm{mmyr}^{-1}\right)$ from TOPAZ4 reanalyses for the period 1993-2016 for (a) the thermosteric contribution, (b) the halosteric contribution, (c) the total steric trend and (d) the total trend. The observed trend from the ESA SL_cci v2.0 data (e).

A positive trend of about $6-7 \mathrm{~mm} \mathrm{yr}^{-1}$ is found in the Beaufort Gyre but appears to extend over a very large area towards the Siberian Shelf, which is not evident in the SL_cci v2.0 dataset. In the Nordic Seas and the Lofoten Basin, regions of both positive and negative trends stand out in contrast to the more gentle sea level rise expressed in the SL_cci v2.0 dataset. Moreover, the large and distinct region of strong decline in the sea level of up to $3-4 \mathrm{~mm} \mathrm{yr}^{-1}$ encountered in the North Atlantic is not found in the SL_cci v2.0 dataset which only shows a very weak decline of around $1 \mathrm{~mm} \mathrm{yr}^{-1}$. Given the uncertainty of the regional sea level trends derived from altimetry and the model, this comparison will contribute to better characterize the ocean circulation changes in this region.

Looking at the Sub-Polar Gyre and the Lofoten Basin, however, one finds that the key contribution to the positive trends in steric and total signals emerge from the thermosteric trends. This is assumed to be related to an increased occupation by warm Atlantic water, which is further 
supported by evidence of corresponding negative halosteric trends that would be expected provided the source is the warm and saline water emerging from the northwestward extension of the Gulf Stream into the North Atlantic Current.

The steric (thermo-, halo-) trends observed in the sea level in the Sub-Polar Gyre have also been discussed by Hatun et al. (2005). They presumed that the variable dynamics of the Sub-Polar Gyre controlled the respective inflows of either cold and fresh sub-polar waters from the East Greenland Current or warm and salty subtropical waters from the Gulf Stream and its extension into the North Atlantic Current (NAC). Using salinity criteria to identify the respective sources of the water masses, they showed opposing transport variability of both source waters. Evidently, this closely mimicked a strong Sub-Polar Gyre when the cold and fresh water transport is strong and a weak Sub-Polar Gyre circulation when the warm and saline water transports dominate the inflow. This suggests a weakening of the anticlockwise circulation in the Sub-Polar Gyre during the last 20-25 years. In contrast, the distinct sea level rise encountered in the Beaufort Gyre during the same period has led to an intensification of the clockwise circulation in the gyre that may stimulate more trapping of fresh and cold Arctic surface water.

The SL_cci v2.0 products have provided new opportunities for studies of sea level changes. The assessment of these products for the high-latitude seas and the Arctic Ocean has focused on the Beaufort Gyre, the Sub-Polar Gyre and the Lofoten Basin in the Norwegian Sea. In so doing we have used the reanalyses from the TOPAZ4 operational system. The inter-comparison and assessment have documented interesting results and sometimes very good agreement and consistency between observations and models. In particular, the findings and achievements include distinct evidence of sea level rise of approximately the following values:

- 4-5 $\mathrm{mm} \mathrm{yr}^{-1}$ for the inner part of the Sub-Polar Gyre explained by the thermosteric contribution together with a barotropic source;

- 6-7 $\mathrm{mm} \mathrm{yr}^{-1}$ for the central Beaufort Gyre explained by the halosteric contribution and accumulation of fresh and cold Arctic water in the gyre;

- 3-4 $\mathrm{mm} \mathrm{yr}^{-1}$ in the inner part of the Lofoten Basin assumed to result from the thermosteric contribution resulting from increased residence time of Atlantic Water in the basin.

Consistent with these findings, it is possible to conclude that a weakening of the anticlockwise circulation has occurred in the Sub-Polar Gyre during the last 20-25 years, while the sea level rise in Beaufort Gyre during the same period has led to an intensification of the clockwise circulation in the gyre with possible trapping of more freshwater.

\subsection{Validation based on the GECCO model of the University of Hamburg}

A further assessment of the quality of the different SL_cci ECVs (v1.1 and v2.0) is provided by comparison with the recent high-resolution GECCO2 ocean synthesis framework (Köhl, 2015). The GECCO2 assimilation approach uses the adjoint method to adjust uncertain model parameters to bring the model into consistency with ocean observations. In this way, the ocean state estimation ultimately leads to new estimates of the surface forcing fields that are required to simulate the observed ocean in the best possible way (given the model resolution and the model physics). The GECCO2 solution covers the period from 1948 to 2011 and had been optimized over 23 iterations. See Köhl (2015) for a description of the GECCO2 ocean state estimate and the datasets used as constraints. Starting from this already optimized state, two additional assimilation runs (G0 and G1.1) were performed as part of this study, all starting from iteration 23, carrying out 5 additional iterations. The only difference between both assimilation runs being the different SSH datasets used as constraints, G0 assimilated the AVISO SSH fields (SL0: DUACS DT2014 now distributed by CMEMS), whereas G1.1 assimilated the SSH fields from SL_cci v1.1 (SL1.1); see Scharffenberg et al. (2017).

Both daily mean GECCO2 synthesis results (G0 and G1.1) were interpolated onto the satellite tracks that matched the respective days for the respective along-track positions to be compared with DUACS DT2014 (SL0), SL_cci v1.1 (SL1.1) and SL_cci v2.0 (SL2.0) satellite datasets. In order to compensate for the scales that the GECCO2 solution is able to resolve, the satellite products SL0 and SL1.1 had to be filtered with an additional running mean filter of 9 points (f9), and SL2.0 with a running mean filter of 11 points (f11). The filter length was determined from the scales that GECCO2 manages to resolve in order to yield similar spectral characteristics of the respective signals, see Scharffenberg et al. (2017) for details. The model data comparisons have been performed separately for the ERS (ERS-1, ERS2 and Envisat) and the TOPEX/Poseidon (TP) satellite series (TOPEX/Poseidon, Jason-1 and Jason2). A smaller difference between model and data residuals implies a better agreement between the GECCO2 model and the satellite datasets.

Figure 14 shows the ratios of RMS-difference-based skill score as defined in Scharffenberg et al. (2017), for the TP (left) and the ERS time series (right). The total improvement due to the updated satellite data SL1.1 and its assimilation into the GECCO2 synthesis can be revealed by the ratio of the differences in G0 and SL0, by using only the DUACS DT2014 dataset SL0, and of the differences in G1.1 and SL1.1 by using the previous updated SL1.1 dataset only. This ratio (G0_SL0) / (G1.1_SL1.1), as shown in Fig. 14a, highlights the reduction in the RMS differences for G1.1_SL1.1 in most regions of the world oceans, leading to an improve- 

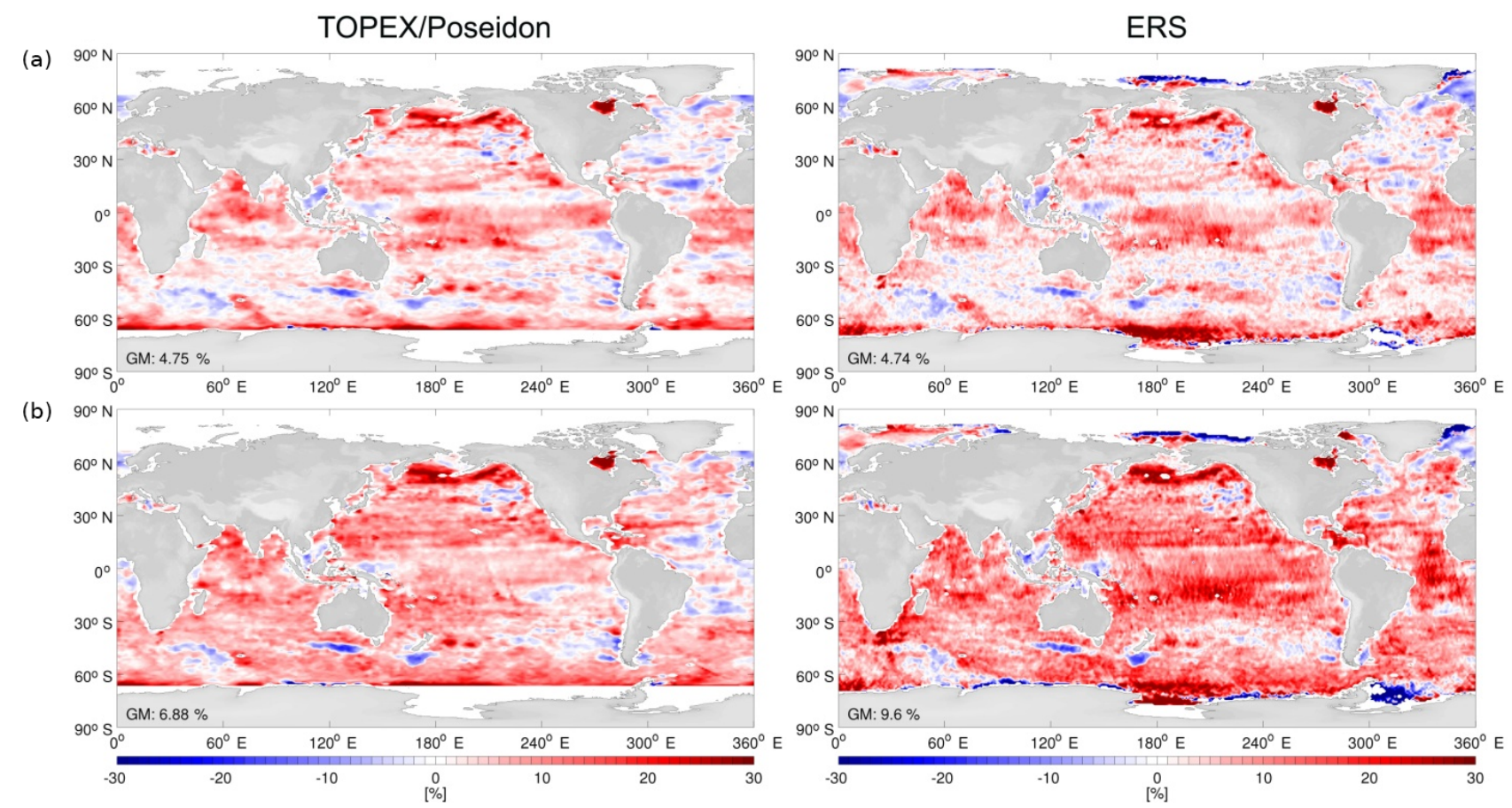

Figure 14. Ratio of RMS differences in low-pass-filtered (f9 or f11) data, for (a) the improvement from DUACS DT2014 (now distributed by CMEMS, previously AVISO) to SL_cci v1.1 as (G0_SL0)/(G1.1_SL1.1), and (b) the total improvement from DUACS DT2014 to SL_cci v2.0 as (G0_SL0)/(G1.1_SL2.0), for TP time series on the left and for ERS time series on the right.

ment (red) of more than $30 \%$ in many regions (e.g. the equatorial regions, the Argentine shelf and parts of the ACC). Additional improvements can be seen in the northern Indian Ocean, the North Pacific, subtropical regions and large regions south of the ACC as well. Degradations of SL1.1 exist in isolated regions, where the GECCO2 synthesis adapts less well to the assimilated SL1.1 product. The regions showing a degradation (blue) match with regions of small SD (see Scharffenberg et al., 2017), implying that the assumption that the model serves as truth breaks down. The global mean improvement (between $66^{\circ} \mathrm{N}$ and $66^{\circ} \mathrm{S}$ ) is 4.75 and $4.74 \%$ for the TP and ERS datasets, respectively.

While the top panel gives the improvement from SL0 to SL1.1, the bottom panel answers the question about the total improvement from the DUACS DT2014 dataset to the latest SL_cci v2.0 ECV. Here, the ratio (G0_SL0) / (G1.1_SL2.0) compares the different assimilation runs G0 and G1.1 while calculating the RMS differences to SL0 and the latest SL_cci ECV SL2.0. The improvement of SL_cci v2.0 ECV has now a more homogenous distribution. Only isolated regions have larger RMS differences for G1.1_SL2.0, especially close to Antarctica as well as in the Arctic regions. The improvements for SL2.0 differ more between the TP and ERS datasets than was the case for SL1.1. Especially in the equatorial regions the ERS dataset has been improved. However, in most other parts of the world's ocean, both satellite datasets see a clear improvement from SL_cci v1.1
(SL1.1) to SL_cci v2.0 (SL2.0), especially in regions where SL1.1 did not improve much compared with SL0. The overall global mean improvement from DUACS DT2014 to SL_cci v2.0 ECV sums up to $6.88 \%$ for the TP dataset and $9.60 \%$ for the ERS dataset. As the GECCO2 synthesis had assimilated SL1.1 but not SL2.0, the GECCO2 synthesis results G1.1 are not expected to be in best agreement to SL2.0.

Furthermore, the GECCO2 synthesis itself benefits from the assimilation of the SL1.1 product as well as has been shown in Scharffenberg et al. (2017). Thereby, the SL_cci v1.1 and 2.0 ECVs, generated by the ESA SL_cci project, have been improved significantly and are now in closer agreement with the GECCO2 synthesis and the various global oceanographic datasets assimilated therein (Köhl, 2015). For a detailed description and assessment of both SL_cci ECVs, we refer to Scharffenberg et al. (2017) and to the SL_cci Climate Assessment Report (SL_cci CAR, 2017).

\subsection{Regional sea level validation: agreement with ocean model outputs}

The gridded SL_cci v2.0 products have also been intercompared and assessed in the Mediterranean Sea against the sea level fields derived from three regional ocean models for the period 1993-2016. Over the shorter period 2002-2014 the assessment includes the comparison of the model steric field with the steric sea level derived from the combination of altimetric and GRACE gravimetric observations. 


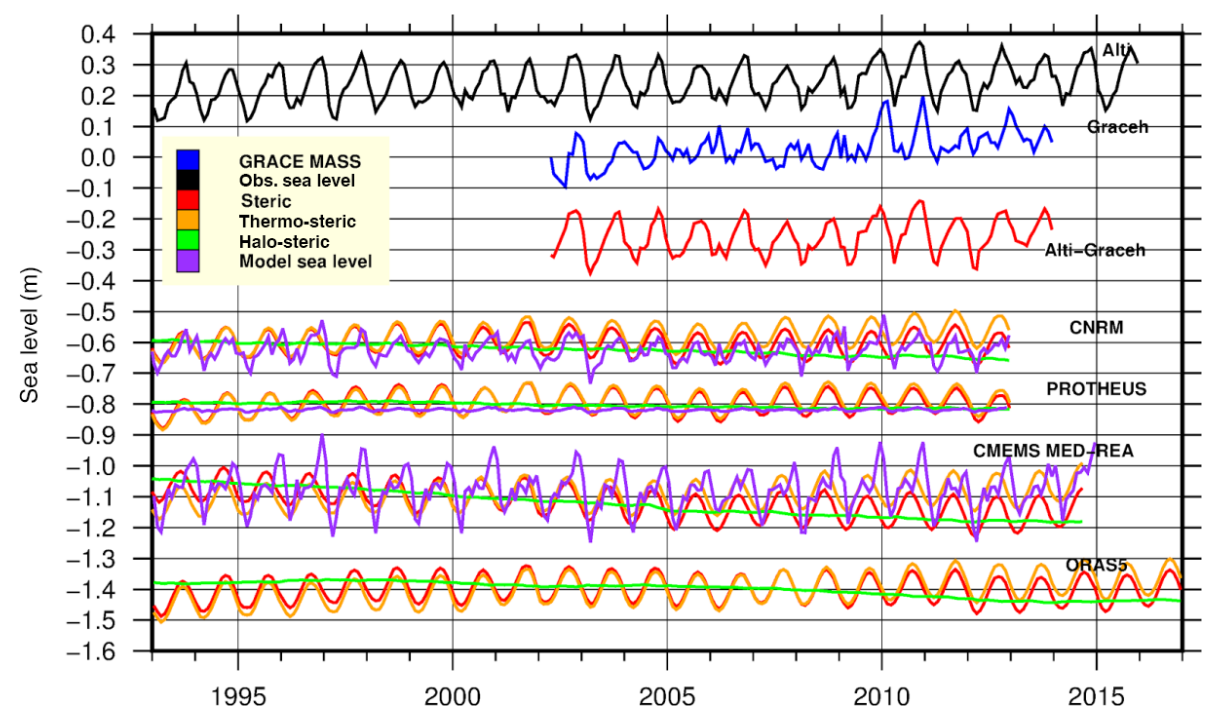

Figure 15. From top to bottom, basin average of altimeter sea level, GRACE mass change, steric derived from altimeter sea level and mass component, steric and sea level components of two simulations, and a regional model reanalysis and a global model reanalysis.

The two ocean simulations are the CNRM-RCM4 (Sevault et al., 2014) and the Protheus (Dell'Aquila et al., 2012); the ocean reanalysis is the CMEMS MEDSEA_REANALYSIS_PHIS_006_004, hereafter MedMFC REA (http://marine.copernicus.eu). The global reanalysis ORAS5 is used as an additional comparison.

The first simulation CNRM-RCM4 is a fully coupled regional climate system model which includes a regional representation of the atmosphere, land surface, rivers and ocean. It is worth noting that the ocean NEMOMED8 model uses the "Boussinesq" approximation (Mellor and Ezer, 1995) and the relaxation of the sea surface height in the Atlantic buffer zone. The same approximation is used in the Protheus model simulation. The regional reanalysis CMEMS MedMFC REA assimilates the DUACS DT2014 SLA (now distributed by CMEMS, previously AVISO).

The model output elevation sea surface height (SSH) and steric components are compared with the observed sea level and to its steric component. The gridded SLA maps from the SL_cci v2.0 ECV and the elevation from the models were interpolated onto the same regular $0.25^{\circ} \times 0.25^{\circ}$ grid to facilitate the intercomparison. The basin averages of the observed sea level, mass change and derived steric sea level component, as well as of the model sea level and steric components, are displayed in Fig. 15. For the models, which use the Boussinesq approximation, the total sea level is the sum of the model sea level and of the steric component basin average. On basin scales we find that the observed sea level agrees at best with the sum of thermo-steric and elevation basin average components. Results are shown for the CNRM model in Fig. 16.

Regional maps of MSL trends from SL_cci v2.0 ECV were evaluated against the SSH from ocean models with the results shown in Fig. 17 for the Protheus simulation and the CMEMS Med-MFC reanalysis. After the subtraction of the average trends of 2.5 and $0.16 \mathrm{~mm} \mathrm{yr}^{-1}$ from the regional ECV and CMEMS model maps (Fig. 17a and e), the trend anomalies from observations and reanalysis show very similar spatial values (Fig. 17b and f). The regional maps of steric, thermo-steric and halo-steric trends are similar in the ocean simulations, and differences between simulation and reanalysis are higher for the halo-steric component.

Basin averages of steric sea level from each model have been compared with the difference of measured total sea level and mass from GRACE. The seasonal amplitude of the model steric component is smaller than the satellitederived steric component and the phase is in good agreement. In Fig. 18, annual basin averages of total sea level, mass-induced sea level and steric component, grouped at the top, middle and bottom of the figure respectively, obtained from observations and models, are represented (for model datasets, the thermo-steric component is used). A significant correlation can be observed between the mass-induced sea surface heights measured by GRACE and both the observed altimeter SSH and the sum of both SSH and thermosteric model component (see Fenoglio-Marc et al., 2012). The model and the steric sea level derived from altimeter and gravimetric observations show a similar long-term variability and some differences to be further investigated.

In summary, in the Mediterranean Sea the main differences on the one hand between the ocean model outputs and on the other hand between the ocean model outputs and the observations are related to the halo-steric component, whose trends have high negative values. 
(a)

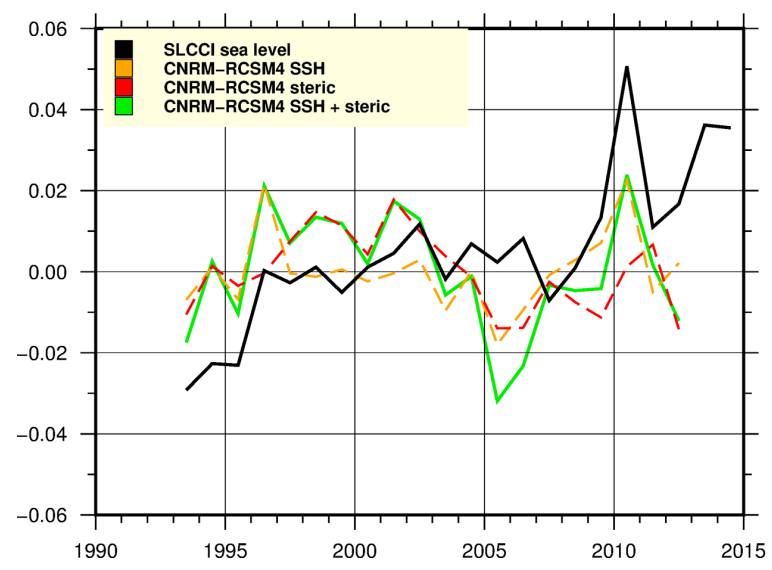

(b)

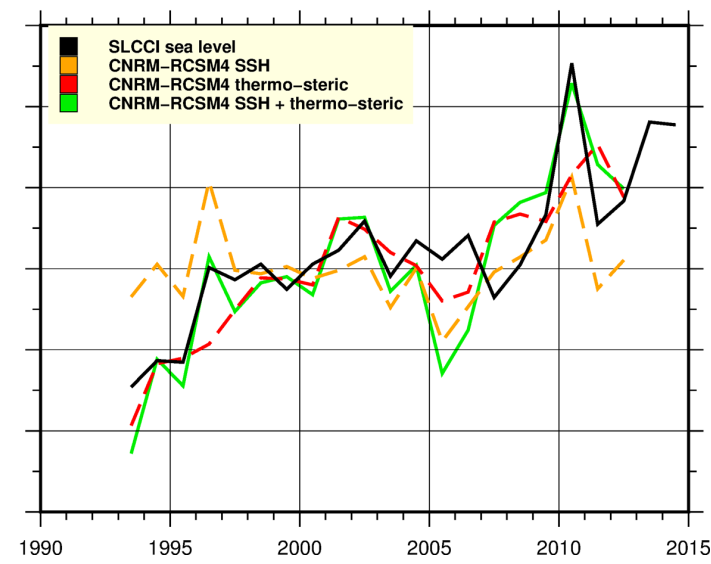

Figure 16. CNRM vs. SL_cci total sea level. (a) Sea surface height (green) from elevation plus steric compared with SL_cci (black), with elevation (orange) and steric (red) components. (b) As in (a) with thermo-steric instead of steric. For both plots, the vertical axis is in metres.

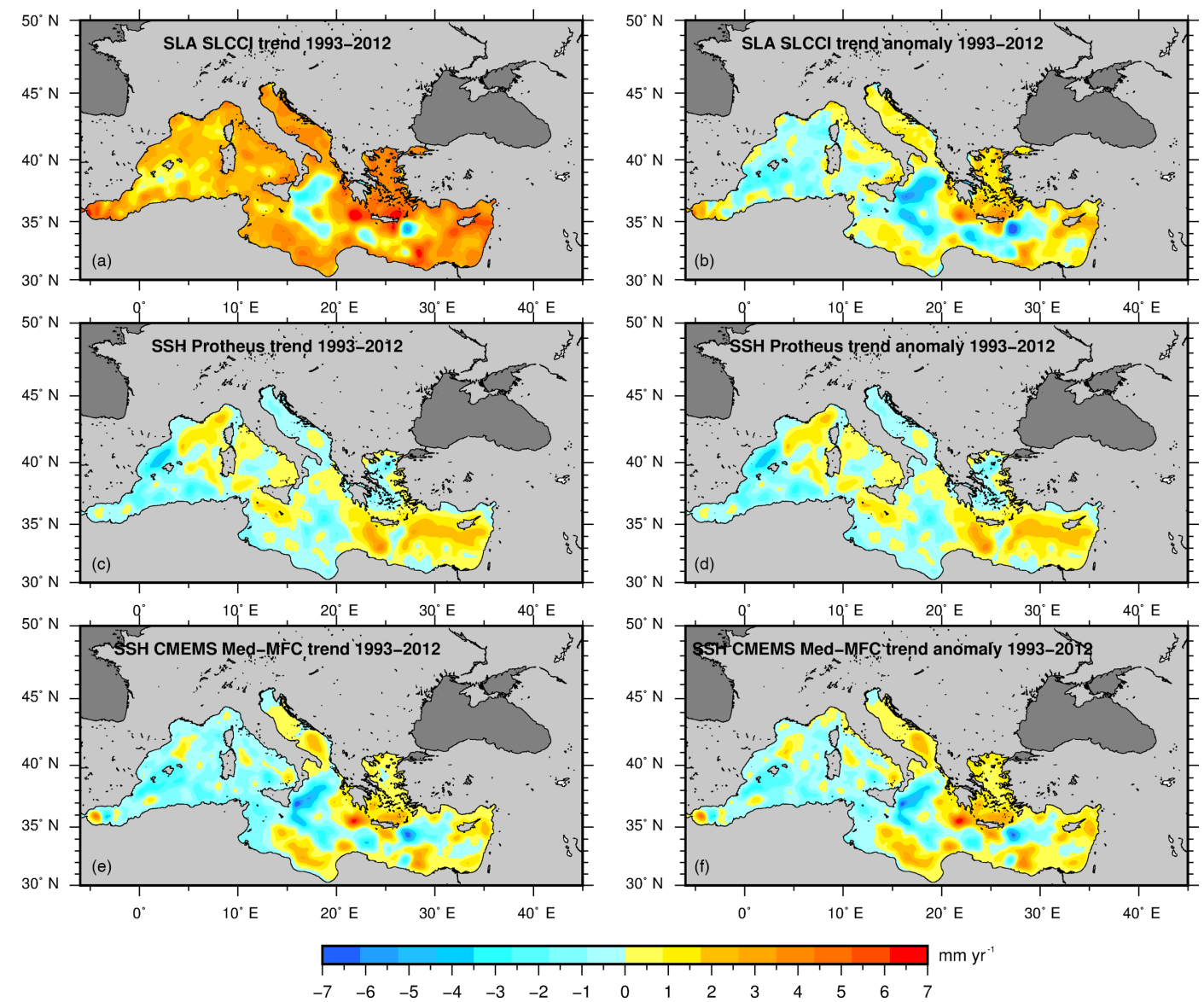

Figure 17. Trend (a, c, e) and trend anomalies (b, d, f) of SSH from SL_cci (a, b) and Protheus model simulation (c, d) and CMEMS reanalysis $(\mathbf{e}, \mathbf{f})$.

\section{MSL error characterization and uncertainties}

Major efforts have been carried out during the past few years to provide a user-oriented error budget of the altimeter sea level estimation. Such an error budget dedicated to the main temporal scales (long-term, inter-annual and seasonal signals) has been established by Ablain et al. (2015) and is given in Table 3. The GMSL trend uncertainty has been estimated 
Table 3. Mean sea level error budget for the main climate scales (Ablain et al., 2015). User requirements are from GCOS (2011).

\begin{tabular}{|c|c|c|c|}
\hline Spatial scales & Temporal scales & Altimetry uncertainties & User requirements \\
\hline Global MSL & $\begin{array}{l}\text { Long-term evolution ( }>10 \text { years) } \\
\text { Inter-annual signals ( }<5 \text { years) } \\
\text { Annual signals }\end{array}$ & $\begin{array}{l}<0.5 \mathrm{~mm} \mathrm{yr}^{-1} \\
<2 \mathrm{~mm} \text { over } 1 \text { year } \\
<1 \mathrm{~mm}\end{array}$ & $\begin{array}{l}0.3 \mathrm{~mm} \mathrm{yr}^{-1} \\
0.5 \mathrm{~mm} \text { over } 1 \text { year } \\
\text { Not defined }\end{array}$ \\
\hline Regional sea level & $\begin{array}{l}\text { Long-term evolution ( }>10 \text { years) } \\
\text { Annual signals }\end{array}$ & $\begin{array}{l}<3 \mathrm{~mm} \mathrm{yr}^{-1} \\
<1 \mathrm{~cm}^{-1}\end{array}$ & $\begin{array}{l}1 \mathrm{~mm} \mathrm{yr}^{-1} \\
\text { Not defined }\end{array}$ \\
\hline
\end{tabular}

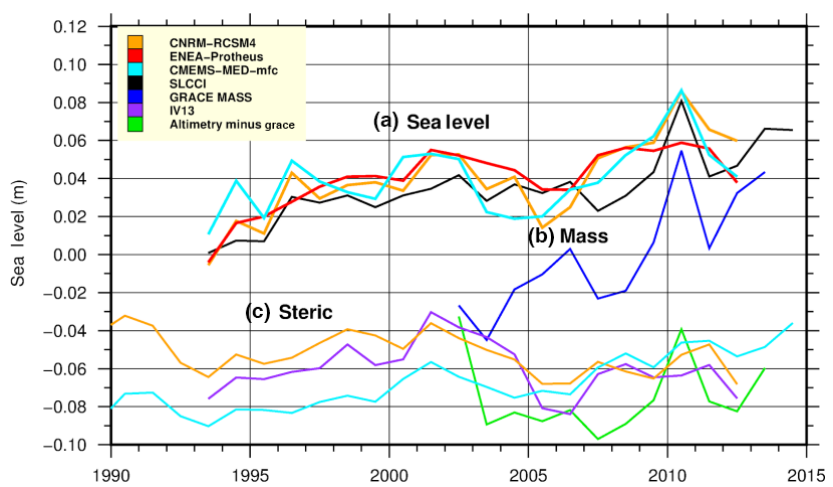

Figure 18. Sea level (a), mass (b) and steric (c) components from SL_cci and GRACE observations and from models. The colour indicates the source, the location in the figure (top, middle or bottom) indicates the type of product (sea level, mass or steric component for the model output).

as $0.5 \mathrm{~mm} \mathrm{yr}^{-1}$ over the whole altimetry era (1993-2015) within a confidence interval of $90 \%$ (1.65 SD). The associated sources of errors are related to some altimeter geophysical standards (Legeais et al., 2014; Couhert et al., 2015), the instabilities of the altimeter parameters (Ablain et al., 2012), the reference frame (Ablain et al., 2015; Couhert et al., 2015) and the issues associated with inter- intra-mission biases and inter-calibration (Zawadzki et al., 2016). As mentioned in Sect. 4.1, the TOPEX-A instrumental drift also contributes significantly to the GMSL uncertainty over the altimetry era. Note that there is not yet consensus on the best way to estimate this correction. Significant inter-annual variations are observed within the GMSL time series (Fig. 1) - mainly attributed to ENSO (Ablain et al., 2017) - and these contribute to the GMSL trend uncertainty in addition to all sources of errors described earlier (Cazenave et al., 2014). An uncertainty envelope for the GMSL has been proposed in order to better characterize inter-annual evolutions.

On a regional scale, the sea level trends vary between $\pm 5 \mathrm{~mm} \mathrm{yr}^{-1}$ around the global mean of $+3 \mathrm{~mm} \mathrm{yr}^{-1}$ and the associated uncertainty is of the order of $2-3 \mathrm{~mm} \mathrm{yr}^{-1}$. On a basin scale, two contributors to the altimeter trend uncertainty can be distinguished. The altimetry errors are one of the contributors. They can be related to the reduced quality of the altimeter sea level estimation in coastal areas (Cipollini et al., 2017) and to the greater error of some geophysical altimeter corrections (ocean tide, inverse barometer and dynamic atmospheric corrections). The second contributor is related to the large internal variability of the observed ocean (and the fact that the associated trend may vary with the length of the record). The local variability is generated by regional changes in winds, pressure and ocean currents which averaged out on a global scale (e.g. Stammer et al., 2013) but this can significantly contribute to the sea level uncertainty on a basin scale. Thus, the users should be aware that there are some regions where the level of uncertainty may be higher than the trend estimations. At last, for both global and regional sea level trends, uncertainties remain higher than the requirements of the GCOS (GCOS, 2011) of $0.3 \mathrm{~mm} \mathrm{yr}^{-1}$ for the GMSL trend and $1 \mathrm{~mm} \mathrm{yr}^{-1}$ for the regional MSL trend (see Table 3). The MSL error characterization is still an ongoing activity within the SL_cci project, and further details regarding error bars and uncertainties will be published when results are finalized.

\section{Data availability}

The sea level CCI database (https://doi.org/10.5270/esa-sea_ level_cci-1993_2015-v_2.0-201612; Legeais and the SL_cci team, 2016c) is freely available (upon email application to info-sealevel@esa-sealevel-cci.org). The sea level CCI website (http://www.esa-sealevel-cci.org/products) presents the gridded monthly files of sea level anomalies (https://doi.org/10.5270/esa-sea_level_cci-MSLA-1993_ 2015-v_2.0-201612) and derived products suitable for some climate studies: global mean sea level temporal evolution (https://doi.org/10.5270/esa-sea_level_cci-IND_MSL_ MERGED-1993_2015-v_2.0-201612); regional mean sea level trends (https://doi.org/10.5270/esa-sea_level_cci-IND_ MSLTR_MERGED-1993_2015-v_2.0-201612); amplitude and phase of annual cycle (https://doi.org/10.5270/esa-sea level_cci-IND_MSLAMPH_MERGED-1993_2015-v_2. 0-201612).

\section{Conclusions and perspectives}

The ESA Climate Change Initiative has provided the opportunity to realize the full potential of the long-term global Earth observations from satellite altimeters. This has led 
to the production of an improved and stable sea level record designed to answer the needs of climate modellers and researchers. The quality assessment of the SL_cci v2.0 ECV has been carried out, distinguishing different temporal and spatial wavelengths and following different approaches: comparisons with the previous version of the ECV and to altimeter products from other groups, sea level budget closure approach, and comparison with model outputs.

Compared with the previous v1.1 version of the SL_cci ECV (Ablain et al., 2015), the main observed differences are related to the updated v2.0 altimeter standards that have been selected within the SL_cci phase II project and used to calculate the altimeter sea level anomalies (see Quartly et al., 2017 for more details on these standards). One of the major differences between both versions is the increased number of altimeters available in the satellite constellation used for the SL_cci v2.0 ECV, compared with the v1.1 ECV. This has led to an improved sea level variance in the reprocessed ECV thanks to the improved sampling of the ocean at the end of the period. This highlights the importance for climate products of using a minimum of two satellites in the sea level ECV production and also to ensure that the number of such satellites remains stable in the constellation.

The different reference time periods used in both versions of the ECV are related to the different mean sea surfaces used to compute the sea level anomalies: DTU10 in v1.1 is referenced to 1993-2008 whereas DTU15 in v2.0 is referenced to 1993-2012. This has to be taken into account in the context of data assimilation for ocean models.

On a global scale, the v2.0 sea level trend is the same as in the v1.1 ECV when considering the total altimeter pe$\operatorname{riod}\left(3.3 \mathrm{~mm} \mathrm{yr}^{-1}\right)$. However, the use of the new GNSS Path delay (GPD+) wet troposphere correction (Fernandes and Lázaro, 2016) significantly affects the trend on a decadal timescale (up to $0.2 \mathrm{~mm} \mathrm{yr}^{-1}$ for each altimeter decade). This is of major importance for sea level budget closure studies which usually focus on the 2005 onwards period. The SL_cci GMSL has not been corrected for the TOPEX-A instrumental drift (recently highlighted by several studies). Even if different approaches have been proposed, there is not yet consensus on the best way to estimate this correction. The recommendation of the Ocean Surface Topography Science Team is to wait for the future release of a reprocessed TOPEX dataset (currently in progress by the space agencies). On the regional scale, up to $\pm 1 \mathrm{~mm} \mathrm{yr}^{-1}$ sea level trend differences are observed compared with the previous version of the ECV and the large-scale differences are associated with the updated orbit solutions used in the v2.0 ECV (Quartly et al., 2017).

Regarding the annual cycle of the sea level, a small difference of amplitude is observed between SL_cci v1.1 and v2.0. Comparisons with the in situ measurements from tide gauges and from the combination of the dynamic heights derived from temperature and salinity profiles of Argo floats and the GRACE ocean mass contribution indicate that the
SL_cci reprocessed ECV is slightly closer to the in situ reference.

The comparisons with the sea level time series from other altimetry groups and budget closure studies have demonstrated the high quality of the reprocessed SL_cci sea level record.

During the project, the altimetry measurement errors and associated uncertainties have been better estimated by separating the main temporal and spatial scales (Ablain et al., 2015). An estimation of sea level uncertainties has highlighted that in some regions, errors are greater than the signal itself. This work will significantly contribute to increasing the accuracy of climate studies. It is worth noting that in spite of the improved altimeter standards used in the product, the GCOS user requirements (GCOS, 2011) are still not reached over some specific spatial and temporal scales (e.g. $0.5 \mathrm{~mm} \mathrm{yr}^{-1}$ uncertainty during the $1993-2015$ period in a $90 \%$ confidence for the GMSL trend compared with the $0.3 \mathrm{~mm} \mathrm{yr}^{-1}$ requirement).

The reprocessed SL_cci v2.0 ECV is thus the state-of-theart sea level ECV available for climate studies. Following the end of the ESA SL_cci project in 2017, the operational production of the sea level ECV has been transferred to the European Copernicus Climate Change Service (C3S), which will set up the routine and sustained production of the ECV. However, a strong need to continue research and development for the sea level record has been identified. Possibilities for evolution include the improvement of the sea level estimation in coastal areas and in ice-covered regions, the better characterization of the sea level uncertainties, and the quality improvement of the altimeter observations. This will contribute to improving the quality of the sea level ECV and achieving the GCOS requirements (GCOS, 2016).

Author contributions. Phase 2 of the Sea Level CCI project was managed by JFL, who oversaw the production and validation of the SL_cci ECV v2.0. The initial draft of the paper was written by JFL with the contributions of GQ for Sect. 2, AC for Sect. 5.1, HZ for Sect. 5.2, JJ for Sect. 5.3, MS for Sect. 5.4 and LFM for Sect. 5.5. Other authors contributed through their revision of the text.

Competing interests. The authors declare that they have no conflict of interest.

Acknowledgements. The authors acknowledge the support of ESA in the frame of the Sea Level CCI project, launched and co-ordinated by technical officer Jérôme Benveniste. It was also made possible thanks to the support of CNES for several years with the use of the DUACS altimeter processing system. We would also like to thank all contributors to this project who have participated actively in the SL_cci project, with special recognition to Sabrina Mbajon Njiche and also Americo Ambrozio and Marco Restano for their support of ESA as well as for their diligent reviewing of 
all the documents and datasets produced by the SL_cci team.

Edited by: Giuseppe M.R. Manzella

Reviewed by: three anonymous referees

\section{References}

Ablain, M. and Legeais, J.-F.: Data Processing Model for the SL_cci system, Ref. CLS-DOS-NT-13-248, nomenclature SLCCI-DPM33, available at: http://www.esa-sealevel-cci.org/webfm_send/ 239 (last access: 7 February 2018), 2014.

Ablain, M., Larnicol, G., Faugere, Y., Cazenave, A., Meyssignac, B., Picot, N., and Benveniste, J.: Error Characterization of Altimetry Measurements at Climate Scales, in: Proceedings of the "20 Years of Progress in Radar Altimetry" Symposium, Venice, 24-29 September 2012, Italy, edited by: Benveniste, J. and Morrow, R., ESA Special Publication SP710, available at: http://www.congrexprojects.com/docs/12c01_ docs/20ypra_abstracts_12_08_27_v9.pdf (last access: 7 February 2018), 2012.

Ablain, M., Cazenave, A., Larnicol, G., Balmaseda, M., Cipollini, P., Faugère, Y., Fernandes, M. J., Henry, O., Johannessen, J. A., Knudsen, P., Andersen, O., Legeais, J., Meyssignac, B., Picot, N., Roca, M., Rudenko, S., Scharffenberg, M. G., Stammer, D., Timms, G., and Benveniste, J.: Improved sea level record over the satellite altimetry era (19932010) from the Climate Change Initiative project, Ocean Sci., 11, 67-82, https://doi.org/10.5194/os-11-67-2015, 2015.

Ablain, M., Legeais, J. F., Prandi, P., Fenoglio-Marc, L., Marcos, M., Benveniste, J., and Cazenave, A.: Satellite altimetrybased sea level at global and regional scales, Surv. Geophys., 38, 9-33, https://doi.org/10.1007/s10712-016-9389-8, 2017.

Barnier, B., Madec, G., Penduff, T., Molines, J.-M., Treguier, A.M., Le Sommer, J., Beckmann, A., Biastoch, A., Böning, C., Dengg, J., Derval, C., Durand, E., Gulev, S., Remy, E., Talandier, C., Theetten, S., Maltrud, M., McClean, J., and De Cuevas, B.: Impact of partial steps and momentum advection schemes in a global ocean circulation model at eddy-permitting resolution, Ocean Dynam., 56, 543-567, https://doi.org/10.1007/s10236009-0180-y, 2006.

Beckley, B. D., Callahan, P. S., Hancock III, D. W., Mitchum, G. T., and Ray, R. D.: On the "cal mode" correction to TOPEX satellite altimetry and its effect on the global mean sealevel time series, J. Geophys. Res.-Oceans, 122, 8371-8384, https://doi.org/10.1002/2017JC013090, 2017.

Bojinski, S., Verstraete, M., Peterson, T. C., Richter, C., Simmons, A., and Zemp, M.: The concept of essential climate variables in support of climate. research, applications, and policy, B. Am. Meteorol. Soc., 95, 1431-1443, https://doi.org/10.1175/BAMS-D-13-00047.1, 2014.

Brown, S.: A novel near-land radiometer wet path-delay retrieval algorithm: application to the Jason-2/OSTM Advanced Microwave Radiometer, IEEE T. Geosci. Remote., 48, 1986-1992, https://doi.org/10.1109/TGRS.2009.2037220, 2010.

Carrere, L., Faugère, Y., and Ablain, M.: Major improvement of altimetry sea level estimations using pressure-derived corrections based on ERA-Interim atmospheric reanalysis, Ocean Sci., 12, 825-842, https://doi.org/10.5194/os-12-825-2016, 2016.
Carret, A., Johannessen, J., Andersen, O., Ablain, M., Prandi, P., Blazquez, A., and Cazenave, A.: Arctic sea level during the altimetry era, Surv. Geophys., 38, 251-275, https://doi.org/10.1007/s10712-016-9390-2, 2016.

Cazenave, A., Dieng, H.-B., Meyssignac, B., von Schuckmann, K., Decharme, B., and Berthier, E.: The rate of sea-level rise, Nat. Clim. Change, 4, 358-361, https://doi.org/10.1038/NCLIMATE2159, 2014.

Chen, G. and Quartly, G. D.: Annual amphidromes: a common feature in the ocean?, IEEE Geosci. Remote S., 2, 425-429, https://doi.org/10.1109/LGRS.2005.854205, 2005.

Chen, J. L., Wilson, C. R., Chambers, D. P., Nerem, R. S., and Tapley, B. D.: Seasonal global water mass budget and mean sea level variations, Geophys. Res. Lett., 25, 1944-8007, https://doi.org/10.1029/98GL02754, 1998.

Chen, X., Zhang, X., Church, J. A., Watson, C. S., King, M. A., Monselesan, D., Legresy, B., and Harig, C.: The increasing rate of global mean sea level-rise during 1993-2014, Nat. Clim. Change, 7, 492-495, https://doi.org/10.1038/NCLIMATE3325, 2017.

Cipollini, P., Birol, F., Fernandes, M. J., Obligis, E., Passaro, M., Strub, P. T., Valladeau, G., Vignudelli, S., and Wilkin, J.: Satellite altimetry in coastal regions, in: Satellite Altimetry Over Oceans and Land Surfaces, edited by: Stammer, D. and Cazenave, A., CRC Press, Taylor \& Francis, Boca Raton, 2017.

Couhert, A., Cerri, L., Legeais, J. F., Ablain, M., Zelensky, N. P., Haines, B. J., Lemoine, F. G., Bertiger, W. I., Desai, S. D., and Otten, M.: Towards the $1 \mathrm{~mm} \mathrm{yr}^{-1}$ stability of the radial orbit error at regional scales, Adv. Space Res., 55, 2-23, https://doi.org/10.1016/j.asr.2014.06.041, 2015.

Dell'Aquila, A., Calmanti, S., Ruti, P., Struglia, M. V., Pisacane, G., Carillo, A., and Sannino, G.: Impacts of seasonal cycle fluctuations in an A1B scenario over the Euro-Mediterranean region, Clim. Res., 52, 135-157, https://doi.org/10.3354/cr01037, 2012.

Desai, S., Wahr, J., and Beckley, B.: Revisiting the pole tide for and from satellite altimetry, J. Geodesy, 89, 1233-1243, https://doi.org/10.1007/s00190-015-0848-7, 2015.

Dieng, H. B., Cazenave, A., Meyssignac, B., and Ablain, M.: New estimate of the current rate of sea level rise from a sea level budget approach, Geophys. Res. Lett., 44, 3744-3751, https://doi.org/10.1002/2017GL073308, 2017.

Escudier, P., Couhert, A., Mercier, F., Mallet, A., Thibaut, P., Tran, N., Amarouche, L., Picard, B., Carrère, L., Dibarboure, G., Ablain, M., Richard, J., Steunou, N., Dubois, P., Rio, M. H., and Dorandeu, J.: Satellite radar altimetry: principle, geophysical correction and orbit, accuracy and precision, in: Satellite Altimetry Over Oceans and Land Surfaces, edited by: Stammer, D. and Cazenave, A., CRC Press, Taylor \& Francis, Boca Raton, 2017.

Fenoglio-Marc, L., Becker, M., Rietbroeck, R., Kusche, J., Grayek, S., and Stanev, E.: Water mass variation in Mediterranean and Black Sea, J. Geodyn., 59-60, 168-182, https://doi.org/10.1016/j.jog.2012.04.001, 2012.

Fernandes, M. J. and Lázaro, C.: GPD+ wet tropospheric corrections for CryoSat-2 and GFO altimetry missions, Remote Sens. Basel, 8, 851-881, https://doi.org/10.3390/rs8100851, 2016.

Fernandes, M. J., Lázaro, C., Ablain, M., and Pires, N.: Improved wet path delays for all ESA and reference altimetric missions, Remote Sens. Environ., 169, 50-74, https://doi.org/10.1016/j.rse.2015.07.023, 2015. 
Fu, L.-L. and Cazenave, A. (Eds.): Satellite altimetry and Earth sciences: A handbook of techniques and applications, Academic Press, San Diego, 463 pp., 2000.

GCOS: Systematic Observation Requirements for Satellite-Based Data Products for Climate (2011 Update) - Supplemental Details to the Satellite-Based Component of the "Implementation Plan for the Global Observing System for Climate in Support of the UNFCCC (2010 Update)", GCOS-154, WMO, Geneva, Switzerland, December 2011.

GCOS: Global Climate Observing System Implementation Plan 2016, GCOS-200, available at: https://library.wmo.int/ opac/doc_num.php?explnum_id=3417 (last access: 7 February 2018), 2016.

Giles, K., Laxon, S., Ridout, A., Wingham, D., and Bacon, S.: Western Arctic Ocean freshwater storage increased by winddriven spin-up of the Beaufort Gyre, Nat. Geosci., 5 194-197, https://doi.org/10.1038/ngeo1379, 2012.

Han, W., Meehl, G. A., Stammer, D., Hu, A., Hamlington, B., Kenigson, J., Palanisamy, H., and Thompson, P.: Spatial patterns of sea level variability associated with natural internal climate modes, Surv. Geophys., 38, 217-250, https://doi.org/10.1007/s10712-016-9386-y, 2017.

Hatun, H., Britt Sando, A., Drange, H., Hansen, B., and Valdimarsson, H.: Influence of the Atlantic Subpolar Gyre on the Thermohaline Circulation, Science, 309, 1841-1844, https://doi.org/10.1126/science.1114777, 2005.

Hayne, G. S. and Handcock, D. W.: Proceedings of the TOPEX/Poseidon/Jason-1 Science Working Team Meeting, October 1998, Keystone, CO, USA, 1998.

IPCC: The Physical Science Basis, in: Contribution of the Working Group I to the Fifth Assessment report of the Intergovernmental Panel on Climate Change, Cambridge University Press, Cambridge, UK, p. 1535, 2013.

Köhl, A.: Evaluation of the GECCO2 ocean synthesis: transports of volume, heat and freshwater in the Atlantic, Q. J. Roy. Meteorol. Soc., 141, 166-181, https://doi.org/10.1002/qj.2347, 2015.

Legeais, J.-F., Ablain, M., and Thao, S.: Evaluation of wet troposphere path delays from atmospheric reanalyses and radiometers and their impact on the altimeter sea level, Ocean Sci., 10, 893905, https://doi.org/10.5194/os-10-893-2014, 2014.

Legeais, J.-F., Prandi, P., and Guinehut, S.: Analyses of altimetry errors using Argo and GRACE data, Ocean Sci., 12, 647-662, https://doi.org/10.5194/os-12-647-2016, 2016a.

Legeais, J.-F., von Schuckmann, K., Dagneaux, Q., Melet, A., Meyssignac, B., Bonaduce, A., Ablain, M., and Pérez Gomez, B.: Sea level, in: von Schuckmann, K., et al., The Copernicus Marine Environment Monitoring Service Ocean State Report, edited by: Taylor and Francis, http://www.tandfonline.com/loi/tjoo20, J. Oper. Oceanogr., 9, s235-s320, https://doi.org/10.1080/1755876X.2016.1273446, 2016b.

Legeais J.-F. and the ESA SL_cci team: the ESA SL_cci ECV v2.0, 10.5270/esa-sea_level_cci-1993_2015-v_2.0-201612 (last access: 7 February 2018), 2016c.

Mellor, G. L. and Ezer, T.: Sea level variations induced by heating and cooling: an evaluation of the Boussinesq approximation in ocean models, J. Geophys. Res., 100, 20565-20577, 1995.

Merrifield, M. A., Thompson, P. R., and Lander, M.: Multidecadal sea level anomalies and trends in the west- ern tropical Pacific, Geophys. Res. Lett., 39, L13602, https://doi.org/10.1029/2012GL052032, 2012.

Meyssignac, B., Salas y Melia, D., Becker, M., Llovel, W., and Cazenave, A.: Tropical Pacific spatial trend patterns in observed sea level: internal variability and/or anthropogenic signature?, Clim. Past, 8, 787-802, https://doi.org/10.5194/cp-8-787-2012, 2012.

Meyssignac, B., Piecuch, C. G., Merchant, C. J., Racault, M.F., Palanisamy, H., MacIntosh, C., Sathyendranath, S., and Brewin, R.: Causes of the regional variability in observed sea level, sea surface temperature and ocean colour over the period 1993-2011, Surv. Geophys., 38, 191-219, https://doi.org/10.1007/978-3-319-56490-6_9, 2017.

Morison, J., Kwok, R., Peralta-Ferriz, C., Alkire, M., Rigor, I., Andersen, R., and Steele, M.: Changing Arctic Ocean freshwater pathways, Nature, 481, 66-70, https://doi.org/10.1038/nature10705, 2012.

Palanisamy, H., Cazenave, A., Delcroix, T., and Meyssignac, B.: Spatial trend patterns in Pacific Ocean sea-level during the altimetry era: the contribution of thermocline depth change and internal climate variability, Ocean Dynam., 65, 341-356, https://doi.org/10.1007/s10236-014-0805-7, 2015a.

Palanisamy, H., Meyssignac, B., Cazenave, A., and Delcroix, T.: Is anthropogenic sea level fingerprint already detectable in the Pacific Ocean?, Environ. Res. Lett., 10, 084024, https://doi.org/10.1088/1748-9326/10/8/084024, 2015 b.

Passaro, M., Kildegaard Rose, S., Andersen, O. B., Boergensa, E., Calafat, F. M., Dettmering, D., and Benveniste, J.: ALES+: adapting a homogenous ocean retracker for satellite altimetry to sea ice leads, coastal and inland waters, Remote Sens. Environ., in review, 2017.

Poisson, J.-C., Quartly, G., Kurekin, A., Thibaut, P., Hoang, D., and Nencioli, F.: Development of an ENVISAT altimetry processor providing sea level continuity between open ocean and Arctic leads, IEEE Geosci. Remote S., accepted, 2017.

Pujol, M.-I., Faugère, Y., Taburet, G., Dupuy, S., Pelloquin, C., Ablain, M., and Picot, N.: DUACS DT2014: the new multimission altimeter data set reprocessed over 20 years, Ocean Sci., 12, 1067-1090, https://doi.org/10.5194/os-12-1067-2016, 2016.

Quartly, G. D., Legeais, J.-F., Ablain, M., Zawadzki, L., Fernandes, M. J., Rudenko, S., Carrère, L., García, P. N., Cipollini, P., Andersen, O. B., Poisson, J.-C., Mbajon Njiche, S., Cazenave, A., and Benveniste, J.: A new phase in the production of quality-controlled sea level data, Earth Syst. Sci. Data, 9, 557-572, https://doi.org/10.5194/essd-9-557-2017, 2017.

Rietbroek, R., Brunnabend, S. E., Kusche, J., Schröter, J., and Dahle, C.: Revisiting the contemporary sea-level budget on global and regional scales, P. Natl. Acad. Sci. USA, 113, 1504 1509, https://doi.org/10.1073/pnas.1519132113, 2016.

Rudenko, S., Dettmering, D., Esselborn, S., Schöne, T., Förste, C., Lemoine, J.-M., Ablain, M., Alexandre, D., and Neumayer, K.-H.: Influence of time variable geopotential models on precise orbits of altimetry satellites, global and regional mean sea level trends, Adv. Space Res., 54, 92-118, https://doi.org/10.1016/j.asr.2014.03.010, 2014.

Rudenko, S., Dettmering, D., Esselborn, S., Fagiolini, E., and Schöne, T.: Impact of Atmospheric and Oceanic De-Aliasing Level-1B (AOD1B) products on precise orbits of altimetry satel- 
lites and altimetry results, Geophys. J. Int., 204, 1695-1702, https://doi.org/10.1093/gji/ggv545, 2016.

Rudenko, S., Neumayer, K.-H., Dettmering, D., Esselborn, S., Schöne, T., and Raimondo, J.-C.: Improvements in precise orbits of altimetry satellites and their impact on mean sea level monitoring, IEEE Geosci. Remote S., 55, 3382-3395, https://doi.org/10.1109/TGRS.2017.2670061, 2017.

Scharffenberg, M. G., Köhl, A., and Stammer, D.: Testing the quality of sea-level data using the GECCO Adjoint Assimilation Approach, Surv. Geophys., 38, 349-383, https://doi.org/10.1007/s10712-016-9401-3, 2017.

Sevault, F., Somot, S., Alias, A., Dubois, C., LebeaupinBrossier, C., Nabat, P., Adloff, F., Deque, M., and Decharme, B.: A fully coupled Mediterranean regional climate system model: design and evaluation of the ocean component for the 1980-2012 period, Tellus A, 66, 23967, https://doi.org/10.3402/tellusa.v66.23967, 2014.

SL_cci Climate Assessment Report (CAR): available at: http:// www.esa-sealevel-cci.org/webfm_send/584, last access: 15 December 2017.

Stammer, D. and Griffies, S.: Ocean modeling and data assimilation in the context of satellite altimetry, in: Satellite Altimetry Over Oceans and Land Surfaces, edited by: Stammer, D. and Cazenave, A., CRC Press, Taylor \& Francis, Boca Raton, 2017.

Stammer, D., Cazenave, A., Ponte, R. M., and Tamisiea, M. E.: Causes for contemporary regional sea-level changes, Annu. Rev. Mar. Sci., 5, 21-46, https://doi.org/10.1146/annurev-marine121211-172406, 2013.

Taylor, K. E.: Summarizing multiple aspects of model performance in a single diagram, J. Geophys. Res., 106, 7183-7192, https://doi.org/10.1029/2000JD900719, 2001.

Tietsche, S., Balmaseda, M. A., Zuo, H., and Mogensen, K.: Arctic sea ice in the global eddy-permitting ocean reanalysis ORAP5, Clim. Dynam., 1-15, https://doi.org/10.1007/s00382-015-26733,2015 .
Valladeau, G., Legeais, J. F., Ablain, M., Guinehut, S., and Picot, N.: Comparing altimetry with tide gauges and Argo profiling floats for data quality assessment and mean sea level studies, Mar. Geod., 35, 20-41, 2012.

von Schuckmann, K. and the CMEMS OSR task team: The Copernicus Marine Environment Monitoring Service Ocean State Report, J. Oper. Oceanogr., 9, s235-s320, https://doi.org/10.1080/1755876X.2016.1273446, 2016.

Wahr, J. W.: Deformation of the Earth induced by polar motion, J. Geophys. Res.-Sol. Ea., 90, 9363-9368, https://doi.org/10.1029/JB090iB11p09363, 1985.

Watson, C. S., White, N. J., Church, J. A., King, M. A., Burgette, R. J., and Legresy, B.: Unabated global mean sea level over the satellite altimeter era, Nat. Clim. Change, 5, 565-568, https://doi.org/10.1038/NCLIMATE2635, 2015.

Wentz, F. J.: SSM/I Version-7 Calibration Report, 011012, Remote Sensing Systems, Santa Rosa, CA, USA, p. 46, 11 January 2013.

Zawadzki, L. and Ablain, M.: Accuracy of the mean sea level continuous record with future altimetric missions: Jason-3 vs. Sentinel-3a, Ocean Sci., 12, 9-18, https://doi.org/10.5194/os12-9-2016, 2016.

Zuo, H., Balmaseda, M. A., and Mogensen, K.: The ECMWFMyOcean2 eddy-permitting ocean and sea-ice reanalysis ORAP5. Part 1: Implementation, ECMWF Tech Memo 736, ECMWF, Reading, England, 2014.

Zuo, H., Balmaseda, M. A., and Mogensen, K.: The new eddypermitting ORAP5 ocean reanalysis: description, evaluation and uncertainties in climate signals, Clim. Dynam., 49, 791-811, https://doi.org/10.1007/s00382-015-2675-1, 2015.

Zuo, H., Balmaseda, M. A., Boisseson, E., Hirahara, S., Chrust, M., and de Rosnay, P.: A new ensemble generation scheme for ocean analysis, ECMWF Tech Memo 795, ECMWF, Reading, England, 2017. 